\title{
Is a more physical representation of aerosol activation needed for simulations of fog?
}

\author{
Craig Poku ${ }^{1, a}$, Andrew N. Ross ${ }^{1}$, Adrian A. Hill ${ }^{2}$, Alan M. Blyth ${ }^{1,3}$, and Ben Shipway ${ }^{2}$ \\ ${ }^{1}$ School of Earth and Environment, University of Leeds, Leeds, UK \\ ${ }^{2}$ Met Office, Exeter, UK \\ ${ }^{3}$ National Centre of Atmospheric Sciences, University of Leeds, Leeds, UK \\ a now at: Wolfson Atmospheric Chemistry Laboratories, University of York, York, UK
}

Correspondence: Craig Poku (craig.poku@york.ac.uk)

Received: 28 August 2020 - Discussion started: 7 September 2020

Revised: 8 April 2021 - Accepted: 8 April 2021 - Published: 12 May 2021

\begin{abstract}
Aerosols play a crucial role in the fog life cycle, as they determine the droplet number concentration and hence droplet size, which in turn controls both the fog's optical thickness and lifespan. Detailed aerosol-microphysics schemes which accurately represent droplet formation and growth are unsuitable for weather forecasting and climate models, as the computational power required to calculate droplet formation would dominate the treatment of the rest of the physics in the model. A simple method to account for droplet formation is the use of an aerosol activation scheme, which parameterises the droplet number concentration based on a change in supersaturation at a given time. Traditionally, aerosol activation parameterisation schemes were designed for convective clouds and assume that supersaturation is reached through adiabatic lifting, with many imposing a minimum vertical velocity (e.g. $0.1 \mathrm{~m} \mathrm{~s}^{-1}$ ) to account for the unresolved subgrid ascent. In radiation fog, the measured updraughts during initial formation are often insignificant, with radiative cooling being the dominant process leading to saturation. As a result, there is a risk that many aerosol activation schemes will overpredict the initial fog droplet number concentration, which in turn may result in the fog transitioning to an optically thick layer too rapidly.

This paper presents a more physically based aerosol activation scheme that can account for a change in saturation due to non-adiabatic processes. Using an offline model, our results show that the equivalent cooling rate associated with the minimum updraught velocity threshold assumption can overpredict the droplet number by up to $70 \%$ in comparison to a typical cooling rate found in fog formation. The
\end{abstract}

new scheme has been implemented in the Met Office Natural Environment Research Council (NERC) Cloud (MONC) large eddy simulation (LES) model and tested using observations of a radiation fog case study based in Cardington, UK. The results in this work show that using a more physically based method of aerosol activation leads to the calculation of a more appropriate cloud droplet number. As a result, there is a slower transition to an optically thick (well-mixed) fog that is more in line with observations.

The results shown in this paper demonstrate the importance of aerosol activation representation in fog modelling and the impact that the cloud droplet number has on processes linked to the formation and development of radiation fog. Unlike the previous parameterisation for aerosol activation, the revised scheme is suitable to simulate aerosol activation in both fog and convective cloud regimes.

\section{Introduction}

Fog can be defined as a cloud at ground level with a surface visibility of less than $1 \mathrm{~km}$ (WMO, 1966). It can cause major disruption to road, aviation and marine transport, with associated economic losses that are comparable to those resulting from winter storms and hurricanes (Gultepe et al., 2007). Fog can have negative impacts on human health and the safety of certain activities. For example, thick fog on 5 September 2013 resulted in the Sheppey Crossing crash in southeast England, consequently injuring 60 people (BBC, 2013). Un- 
derstanding the physics behind fog is crucial in improving fog forecasting and mitigating the impact of such events.

An uncertainty within fog forecasting is caused by aerosol-fog interaction representation (Pruppacher and Klett, 2010). Aerosols are important for both clouds and fog, as they act as the substrate on which water condenses and droplets form. The growth rate of these droplets is dependent on the initial aerosol size and solubility. The aerosols are considered to be "activated" once these droplets reach a certain size, where they can grow more easily within a saturated environment (known as cloud condensation nuclei, CCN). The aerosol population is split by size categories. These size categories (hereafter known as modes) are technically defined as the Aitken mode, where the diameter, $d$, of an aerosol particle is $<0.1 \mu \mathrm{m}$; the accumulation mode, where $0.1 \leq d \leq 1.0 \mu \mathrm{m}$; and the coarse mode, where $d>1.0 \mu \mathrm{m}$ (Whitby, 1978). Due to their size, Aitken-mode aerosols have an increased tendency to coagulate with other particles and not activate in their own right. In contrast, accumulation- and coarse-mode aerosols can activate into fog droplets, therefore indirectly impacting the cloud's microphysical structure and its lifespan (e.g. Twomey, 1974; Albrecht, 1989). These impacts have been studied in great depth over the last few decades, both in the context of climate (e.g. IPCC, 2001) and meteorology (e.g. Seifert and Heus, 2013; Miltenberger et al., 2018). While research into radiation fog spans the last 100 years (e.g. Taylor, 1917; Roach et al., 1976), studies investigating aerosol impacts on fog are more recent. For example, Bott (1991) shows that aerosols fundamentally control radiation fog's optical thickness, and additional studies (e.g. Stolaki et al., 2015; Maalick et al., 2016) have verified why it is critical to correctly represent different aerosol indirect effects when simulating fog.

Accurate droplet nucleation representation, i.e. aerosol activation, is essential to represent the aerosol indirect effects on clouds. However, when investigating aerosol-cloud interactions in models such as general circulation models (GCMs) and numerical weather prediction (NWP) models, many detailed droplet growth schemes are unsuitable, as the computational power required would dominate the treatment of the rest of the physics in the model (Ghan et al., 1993). Original development of an aerosol activation parameterisation began by Squires (1958), with work by Twomey (1959) expanding on the modelling of aerosol activation. Twomey (1959) discussed the link between an aerosol spectrum, supersaturation and droplet number concentration. Using Köhler theory, Twomey (1959) formulated a parameterisation based on the change in supersaturation for a given time, such that

$$
\frac{\mathrm{d} s}{\mathrm{~d} t}=\alpha-\beta s \int_{0}^{s} v(\sigma)\left[\int_{\tau(\sigma)}^{t} s \mathrm{~d} t\right]^{\frac{1}{2}} \mathrm{~d} \sigma,
$$

where $\alpha$ is the supersaturation source due to atmospheric cooling, with the second term of Eq. (1) representing water vapour condensation onto the activated aerosol population. The constant, $\beta$, is dependent on the aerosol spectrum, with $v(\sigma) \delta \sigma$ being the number of nuclei in a unit volume with critical supersaturation between $\sigma$ and $\sigma+\delta \sigma$. As condensation results in a decrease in supersaturation, the maximum number of activated aerosols is capped and will occur once the peak supersaturation is reached (i.e. when the condensation term starts to dominate the cooling terms), resulting in no more aerosols activating. At this point, $\frac{\mathrm{d} s}{\mathrm{~d} t}=0$, and Eq. (1) becomes

$\alpha=\beta s \int_{0}^{s} v(\sigma)\left[\int_{\tau(\sigma)}^{t} s \mathrm{~d} t\right]^{\frac{1}{2}} \mathrm{~d} \sigma$.

Different authors have addressed solving the right-hand side of Eq. (2). Twomey (1959) formulated an upper and lower bound to the inner integral in Eq. (2) and assumed an aerosol spectrum, which was later developed further by Cohard et al. (1998), Shipway and Abel (2010), and Shipway (2015). Ghan et al. (1993) developed a scheme that accounted for a more realistic aerosol size distribution, which was naturally bounded by the total aerosol number. They showed that accounting for a more realistic singlemode aerosol size distribution (lognormal) improved the parameterised number of droplets activated. However, because droplet growth was neglected upon activation in their scheme, the introduction of multi-mode aerosol resulted in big discrepancies between the explicit and parameterised number of activated droplets. Work by Abdul-Razzak et al. (1998) (and later Abdul-Razzak and Ghan, 2000) combined the benefits of the parameterisations developed by both Twomey (1959) and Ghan et al. (1993). The scheme was not only bound by the total aerosol number but also assumed that growth continued from the point of activation. The result of these assumptions led to the parameterised number of activated aerosols agreeing better with the explicit calculation for activation, even in regimes of high updraught velocities (Abdul-Razzak and Ghan, 2000). There has also been work to move away from using aerosol activation schemes in fog simulations using large eddy simulations. Recent work by Schwenkel and Maronga (2019) has shown that the choice in condensation calculation can be critical when investigating aerosol-fog interactions using large eddy simulations. More specifically, the same authors followed this study by demonstrating that using a bulk microphysics scheme in comparison to a Lagrangian cloud model (LCM) can overestimate liquid water and inaccurately represent the fog droplet distribution (Schwenkel and Maronga, 2020). However, using methods such as LCMs is unsuitable for weather and climate models due to their massive computational expense.

So far, the activation schemes discussed that are suitable for weather and climate models (i.e. Cohard et al., 1998; Abdul-Razzak et al., 1998; Abdul-Razzak and Ghan, 2000; Shipway, 2015) have been tested assuming that saturation 
is driven by adiabatic ascent. In addition, a number of the listed schemes impose a fixed minimum updraught velocity threshold, $w_{\min }$, of $0.1 \mathrm{~m} \mathrm{~s}^{-1}$, corresponding to a cooling rate of $3.51 \mathrm{~K} \mathrm{~h}^{-1}$ assuming a dry adiabatic lapse rate (e.g. Ghan et al., 1997; Abdul-Razzak and Ghan, 2000; Morrison and Gettelman, 2008; West et al., 2014). A $w_{\min }$ is suitable for these schemes, as they are designed to consider updraughts found in stratocumulus and convective clouds (Abdul-Razzak and Ghan, 2000; Meskhidze et al., 2005). Furthermore, some models (such as GCMs) will use the subgrid velocity (derived from the subgrid turbulence) to calculate the number of droplets. However, the turbulence driven by cloud-top radiative cooling can be poorly resolved above the planetary boundary layer (PBL) unless the model's vertical resolution was $<100 \mathrm{~m}$ (Ghan et al., 1997). Since such resolutions are not feasible in operational NWP or climate models, a $w_{\min }$ of $0.1 \mathrm{~m} \mathrm{~s}^{-1}$ is imposed to account for this unresolved turbulence (Ghan et al., 1997). In radiation fog, the main mechanism for the initial formation of droplets is radiative cooling - a non-adiabatic process, with measured cooling rates of $1-4 \mathrm{~K} \mathrm{~h}^{-1}$ at the surface (calculated using data from Price, 2011) and updraught velocities close to $0 \mathrm{~m} \mathrm{~s}^{-1}$. Consequently, both the assumption of saturation being driven by adiabatic ascent and the use of a minimum vertical velocity threshold do not accurately account for aerosol activation in fog (as discussed in Boutle et al., 2018). Finally, although there are studies that focus on investigating using a nonadiabatic framework in aerosol activation schemes when simulating fog (e.g. Zhang et al., 2014; Schwenkel and Maronga, 2019), there are no studies to the authors' knowledge that test these assumptions for fog formation in clean aerosol regimes. Therefore, this may mean that using their schemes to simulate rural fog cases may lead to an overestimation in condensation (Shipway, 2015).

This paper will focus on addressing the physical assumptions used in present activation schemes when simulating aerosol-fog interactions in radiation fog. To test these assumptions in our work, we will be utilising both the original and modified version of the Shipway (2015) scheme. It was chosen to use Shipway over Abdul-Razzak and Ghan (2000) (hereafter referred to as ARG) as it has been shown that ARG overestimates condensation in low aerosol regimes, making it activate too few aerosols (Shipway, 2015). The work presented in this paper has been split into two sections: firstly comparing the original Shipway scheme (henceforth Shipway) with the modified Shipway scheme developed here (SMOD) using an offline box model, and secondly comparing both of these schemes using large eddy simulations (LESs) of an idealised fog case study (as described in Poku et al., 2019). During both comparisons, the following questions will be addressed:

1. What are the potential differences in aerosol activation between the Shipway and SMOD scheme?
2. How do the differences in aerosol activation representation impact the fog evolution in a large eddy simulation?

3. What potential discrepancies are not accounted for when simulating aerosol-fog interactions?

Section 2 will present how the Shipway and SMOD schemes differ from each other mathematically. Section 3 will outline the Shipway box model setup and how the SMOD was implemented into it. Section 4 addresses research question 1. Section 5 describes the LES model used and addresses research question 2. A discussion and conclusion will then follow.

\section{SMOD - modifying the Shipway activation scheme to include non-adiabatic cooling}

\subsection{Shipway activation scheme}

The Shipway (2015) aerosol activation scheme is designed as an improvement to the original lower bound approximation by Twomey (1959) and utilises a lookup table method that solves the maximum supersaturation at a reduced computational expense. Shipway assumes the differential activity spectrum, $\phi(s)$, to be lognormal, which can be expressed as

$\phi(s)=\sum_{i=1}^{I} \frac{N_{i}}{\sqrt{2 \pi} \ln \left(\sigma_{s, i}\right) s} \exp \left(-\frac{\ln ^{2}\left(s / s_{0, i}\right)}{\ln ^{2} \sigma_{s, i}}\right)$,

where $N_{i}$ is the number concentration of dry aerosol, $\sigma_{s, i}$ is the standard deviation of the distribution of $\phi(s)$ and $s_{0, i}$ is the mean geometric supersaturation for each given aerosol mode. Shipway (2015) formulated a new expression for the maximum supersaturation using the original Twomey (1959) lower bound approximation, such that

$$
\begin{aligned}
\frac{\sqrt{2} \alpha^{\frac{3}{2}}}{\gamma}= & s_{\max } \int_{0}^{s_{\max }} \phi(\sigma)\left[\frac{1}{2}\left(1-\left(\frac{\sigma}{s_{\max }}\right)^{\mu}\right)^{\lambda}\right]^{-1} \\
& \left(s_{\max }^{2}-\sigma^{2}\right)^{\frac{1}{2}} \mathrm{~d} \sigma,
\end{aligned}
$$

where $\mu$ and $\lambda$ are chosen empirically by Shipway (2015) such that $\mu=3$ and $\lambda=0.6$. $\alpha$ relates to the increase in relative humidity and hence saturation, due to an air parcel undergoing atmospheric cooling. To date, the Shipway activation scheme assumes that $\alpha$ is driven by an updraught velocity, i.e.

$\alpha=\psi(T, p) \frac{\mathrm{d} z}{\mathrm{~d} t}$,

where $\psi(T)$ is the thermodynamical function associated with a change in supersaturation and pressure due to adiabatic ascent, with

$\psi=\frac{c_{p}}{R_{\mathrm{a}} T}-\frac{L}{R_{\mathrm{v}} T^{2}}$, 
where $L$ is the specific latent heat of vaporisation, and $\gamma$ is a temperature pressure variable related to the change in temperature due to latent heat release, such that

$\gamma=\frac{p}{\epsilon e_{\mathrm{S}}}+\frac{L^{2}}{R_{\mathrm{v}} c_{p} T^{2}}$.

Using a precalculated lookup table to solve the right-hand side of Eq. (4) and again $s_{\max }$, Shipway (2015) calculates the total number of activated aerosols, $N_{\text {act }}$ :

$N_{\text {act }}=\frac{N_{i}}{2}\left[1+\operatorname{erf}\left(\frac{\ln \left(s_{\max } / s_{0, i}\right)}{\sqrt{2} \ln \sigma_{s, i}}\right)\right]$,

with $\operatorname{erf}(x)$ being the error function (Abramowitz and Stegun, 1964). For the SMOD scheme (see Appendix A for further details), the term $\alpha$ in Eq. (4) has been modified to account for non-adiabatic cooling, such that

$\alpha=\left.\psi_{1} \frac{\mathrm{d} T}{\mathrm{~d} t}\right|_{\mathrm{ad}}+\left.\psi_{2} \frac{\mathrm{d} T}{\mathrm{~d} t}\right|_{\text {non_ad }}$,

where

$$
\begin{aligned}
& \psi_{1}=\frac{c_{p}}{R_{\mathrm{a}} T}-\frac{L}{R_{\mathrm{v}} T^{2}}, \\
& \psi_{2}=-\frac{L}{R_{\mathrm{v}} T^{2}} .
\end{aligned}
$$

The SMOD scheme differs from Shipway when calculating $N_{\text {act }}$ in that it uses Eq. (9) to solve $s_{\max }$ (see Table A1 in Shipway, 2015, for a summary of terms described in this section and Appendix A for a full derivation of $\psi_{1,2}$ ). This term has also been used in previous studies such as Schwenkel and Maronga (2019) when investigating nocturnal radiation fog using LES.

\section{The Shipway box model - offline setup}

To understand the flexibility of the SMOD scheme and how the thermodynamical function associated with the nonadiabatic contribution may impact $N_{\text {act }}$, both the Shipway and extended SMOD activation schemes will be directly compared using the Shipway box model (Shipway, 2015). The Shipway box model is designed as a non-interactive offline suite to calculate the initial number of activated aerosols in a range of different environmental settings. As the model is non-interactive, it permits analysis of parameter space in the absence of atmospheric feedbacks. Inputs of the model are potential temperature, vertical velocity and aerosol population properties (number concentration, size, mode and distribution size parameters). Shipway (2015) used the box model to test the Shipway (2015) and Twomey (1959) activation schemes in different aerosol regimes, in addition to schemes developed by Abdul-Razzak and Ghan (2000) and Nenes and Seinfeld (2003).

For this work, the Shipway activation scheme was modified to account for a temperature change due to both adiabatic and non-adiabatic processes, using Eq. (9). Aerosol loadings from Whitby (1978) were used to test both activation schemes. These properties considered different environments, ranging from clean to polluted (Table 1). The temperature was set as a fixed value of $274 \mathrm{~K}$, based on surface temperatures observed during fog formation (Price, 2011; Haeffelin et al., 2013). All tests were driven by cooling rates found in fog formation (1-4 $\mathrm{K} \mathrm{h}^{-1}$ calculated using data from Price, 2011) and also accounted for a temperature change due to a nocturnal clear-sky cooling $\left(0-1 \mathrm{~K} \mathrm{~h}^{-1}\right.$; Kiehl and Trenberth, 1997).

Tables 2 and 3 display the case setups used in the offline box model, including the list of tests conducted in each case. Table 2 lists all the tests that directly compares the Shipway and SMOD scheme, based on Eqs. (4) and (9). Each scheme is tested with all combinations of the three different environments (marine, clean continental and urban) and the three different aerosol modes (Aitken, accumulation and coarse). To check that the SMOD scheme was correctly coded into the box model, meaning that supersaturation can be driven by a cooling rate rather than an updraught velocity, the nonadiabatic term in SMOD and $w_{\min }$ was set to zero. Conducting this case would also test the aerosol activation's sensitivity to the choice in aerosol mode.

Further cases (details in Table 3) were run in order to identify the impact of $w_{\min }$ in the Shipway scheme and the impact of the non-adiabatic term in SMOD. For this case, the following three representations were used.

1. SMOD, which accounted for both adiabatic and nonadiabatic cooling. For these tests, $w_{\min }=0 \mathrm{~m} \mathrm{~s}^{-1}$ and the adiabatic cooling component was switched off.

2. Default Shipway scheme. Cooling is assumed to be adiabatic, with $w_{\min }=0.1 \mathrm{~m} \mathrm{~s}^{-1}$.

3. Shipway scheme, with cooling assumed to be adiabatic and $w_{\min }=0 \mathrm{~m} \mathrm{~s}^{-1}$ (i.e. assuming no additional subgrid cooling). This might be more appropriate for use in an LES where vertical motion is well resolved.

Firstly, a comparison between Shipway with no $w_{\min }$ and Shipway in its default setting (with an applied $w_{\min }=$ $0.1 \mathrm{~m} \mathrm{~s}^{-1}$ ) tested the suitability of a $w_{\min }$ in fog modelling. This comparison was motivated by Boutle et al. (2018), who discussed how aerosol activation in fog can be overestimated by the use of a $w_{\min }$ value designed for convective clouds. The results of this test will quantify this overestimation and hence guide how $w_{\min }$ may require modification for fog modelling. Next, a comparison between SMOD and Shipway with $w_{\min }=0 \mathrm{~m} \mathrm{~s}^{-1}$ tested the suitability of assuming adiabatic cooling in a non-adiabatic environment. 
Table 1. Aerosol properties used to test the Shipway and SMOD schemes in the Shipway box model (Whitby, 1978).

\begin{tabular}{llrrr}
\hline Environmental setting & Distribution parameters & Aitken mode & Accumulation mode & Coarse mode \\
\hline Marine & $N\left(\mathrm{~cm}^{-3}\right)$ & 340 & 60 & 3.1 \\
& $\sigma$ & 1.6 & 2.0 & 2.7 \\
& $r(\mu \mathrm{m})$ & 0.005 & 0.035 & 0.31 \\
\hline Clean continental & $N\left(\mathrm{~cm}^{-3}\right)$ & 1000 & 800 & 0.72 \\
& $\sigma$ & 1.6 & 2.1 & 2.2 \\
& $r(\mu \mathrm{m})$ & 0.008 & 0.034 & 0.46 \\
\hline \multirow{2}{*}{ Urban } & $N\left(\mathrm{~cm}^{-3}\right)$ & 10600 & 32000 & 5.4 \\
& $\sigma$ & 1.8 & 2.16 & 2.21 \\
& $r(\mu \mathrm{m})$ & 0.007 & 0.027 & 0.43 \\
\hline
\end{tabular}

Table 2. The tests conducted in the offline box model that directly compared the Shipway and SMOD adiabatic mode based on Eqs. (4) and (9).

\begin{tabular}{|c|c|c|c|c|}
\hline Case & Tests in case & Scheme used & Aerosol mode & Environment \\
\hline C_ship_ad_mar & $\begin{array}{l}\text { T_ship_mar_ait } \\
\text { T_ship_mar_acc } \\
\text { T_ship_mar_coa }\end{array}$ & Shipway & $\begin{array}{l}\text { Aitken } \\
\text { Accumulation } \\
\text { Coarse }\end{array}$ & Marine \\
\hline C_ship_ad_con & $\begin{array}{l}\text { T_ship_con_ait } \\
T \text { _ship_con_acc } \\
T \text { _ship_con_coa }\end{array}$ & Shipway & $\begin{array}{l}\text { Aitken } \\
\text { Accumulation } \\
\text { Coarse }\end{array}$ & Clean continental \\
\hline C_ship_ad_urb & $\begin{array}{l}\text { T_ship_urb_ait } \\
\text { T_ship_urb_acc } \\
\text { T_ship_urb_coa }\end{array}$ & Shipway & $\begin{array}{l}\text { Aitken } \\
\text { Accumulation } \\
\text { Coarse }\end{array}$ & Urban \\
\hline C_SMOD_ad_mar & $\begin{array}{l}\text { T_SMOD_mar_ait } \\
\text { T_SMOD_mar_acc } \\
\text { T_SMOD_mar_coa }\end{array}$ & SMOD & $\begin{array}{l}\text { Aitken } \\
\text { Accumulation } \\
\text { Coarse }\end{array}$ & Marine \\
\hline C_SMOD_ad_con & $\begin{array}{l}\text { T_SMOD_con_ait } \\
\text { T_SMOD_con_acc } \\
\text { T_SMOD_con_coa }\end{array}$ & SMOD & $\begin{array}{l}\text { Aitken } \\
\text { Accumulation } \\
\text { Coarse }\end{array}$ & Clean continental \\
\hline C_SMOD_ad_urb & $\begin{array}{l}\text { T_SMOD_urb_ait } \\
\text { T_SMOD_urb_acc } \\
\text { T_SMOD_urb_coa }\end{array}$ & SMOD & $\begin{array}{l}\text { Aitken } \\
\text { Accumulation } \\
\text { Coarse }\end{array}$ & Urban \\
\hline
\end{tabular}

\section{Testing Shipway and SMOD schemes using an offline box model}

\subsection{Behaviours of the Shipway and SMOD schemes in low-updraught-velocity regimes}

This section's objective is to understand the relative importance of different aerosol modes concerning aerosol activation in fog and to check that the adiabatic pathway in the SMOD scheme was coded correctly. Although the implementation for SMOD is different in that it applies a cooling rate rather than an updraught velocity, these tests comparing Shipway to SMOD should produce identical results for a given equivalent cooling rate.
When comparing the code that would control the adiabatic pathways in the Shipway and SMOD scheme, the differences in numerical calculations are negligible across all tests, which is shown by the overlapping dashed line over the solid line for all tests in Fig. 1. Figure 1a shows a monotonic increase in the maximum supersaturation, $s_{\max }$, across all environments with respect to updraught velocity. For a fair comparison, an equivalent cooling rate was calculated for the SMOD scheme using the dry adiabatic lapse rate assumption (see Eq. A6 in Appendix A). The $s_{\max }$ is $0.26 \%$ for the marine environment, corresponding to a cooling rate of $4 \mathrm{~K} \mathrm{~h}^{-1}$, and decreases as the aerosol concentration increases $(0.11 \%$ and $0.04 \%$ for the clean continental and urban environment respectively). The decrease in $s_{\max }$ with increases in aerosol 
Table 3. The tests conducted in the offline box model used to test activation scheme representation and appropriate use of $w_{\text {min }}$.

\begin{tabular}{|c|c|c|c|c|c|c|}
\hline Case & Tests in case & Scheme used & Cooling source & $w_{\min }$ applied & Aerosol mode & Environmen \\
\hline \multirow[t]{3}{*}{ C_accumulation_mar } & T_ship_mar_acc & Shipway & Adiabatic & \multirow{3}{*}{$\mathrm{X}$} & Accumulation & Marine \\
\hline & T_ship_mar_acc_wmin & Shipway & Adiabatic & & & \\
\hline & T_SMOD_mar_acc & SMOD & Non-adiabatic & & & \\
\hline \multirow[t]{3}{*}{ C_accumulation_con } & T_ship_con_acc & Shipway & Adiabatic & \multirow{3}{*}{$\mathrm{X}$} & Accumulation & Clean \\
\hline & T_ship_con_acc_wmin & Shipway & Adiabatic & & & continental \\
\hline & T_SMOD_con_acc & SMOD & Non-adiabatic & & & \\
\hline \multirow[t]{3}{*}{ C_accumulation_urb } & T_ship_urb_acc & Shipway & Adiabatic & \multirow{3}{*}{$\mathrm{X}$} & Accumulation & Urban \\
\hline & T_ship_urb_acc_wmin & Shipway & Adiabatic & & & \\
\hline & T_SMOD_urb_acc & SMOD & Non-adiabatic & & & \\
\hline
\end{tabular}
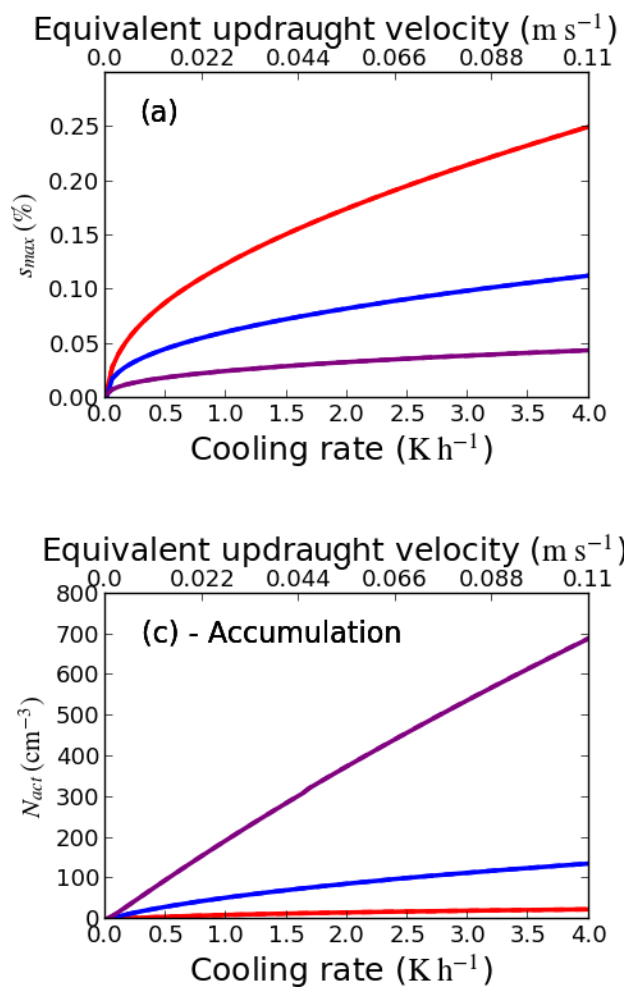
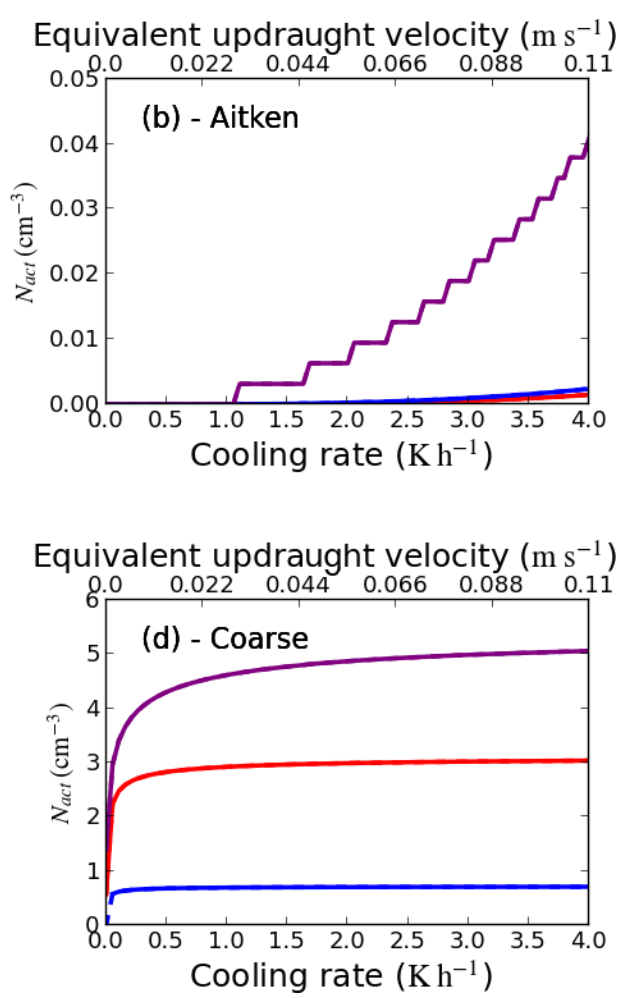

Figure 1. (a) Maximum supersaturation, $s_{\max }(\%)$, against the total cooling rate. (b-d) A plot of activated aerosol concentration, $N_{\text {act }}\left(\mathrm{cm}^{-3}\right)$, against the total cooling rate for Aitken-, accumulation- and coarse-mode aerosols respectively. Red - marine; blue - clean continental; purple - urban. Solid line - T_ship_ad; dashed line - T_SMOD_ad (solid line overlying the dashed line).

concentration relates to increased water vapour competition and hence condensation rate, resulting in a reduced likelihood of newly activated droplets.

Figure 1b-d show an increase in activated aerosols in relation to cooling rate. Of the three modes, the proportion of activated aerosols is greatest in the accumulation mode in all tested environments. This is even though in some environments (e.g. marine) the proportion of aerosol in the Aitken mode is greater than the accumulation mode (see Table 1). The relatively small radii of Aitken-mode aerosol compared to the rest of the aerosol spectrum makes the required max- imum supersaturation for activation significantly higher, as displayed in Fig. 1b. The reality is that supersaturation levels in fog have been shown to only reach several tenths of $1 \%$ (Gerber, 1991) and hence would not be great enough to activate Aitken-mode aerosol. Given the result of this test, it could indicate that nocturnal fog simulations that account for aerosol activation can neglect the Aitken mode. This will be discussed further in Sect. 5. Although there is an increase in $N_{\text {act }}$ with respect to updraught velocity for Aitkenmode aerosol (Fig. 1b), the aerosol activation fraction is so small that it leads to a visible stepwise function (this being 
strongest in the urban environment). The stepwise behaviour for the Aitken mode is a result of poor resolution in the lookup table for the Shipway scheme at low updraught velocities, where this behaviour has been highlighted due to $w_{\min }$ not being present. The resolution could be improved by using a more robust integration method. However, changing the integration method does not impact the general conclusions relating to the new scheme, and hence this will be explored in later work.

\subsection{Associated percentage difference for methods of aerosol activation}

To understand how $N_{\text {act }}$ may be impacted by the choice in aerosol activation representation, accumulation-mode tests displayed in Table 3 were rerun using the SMOD activation scheme and the Shipway (2015) scheme with an applied $w_{\min }$. Although these same tests were run for Aitken- and coarse-mode aerosol (see Table 1), there was little to no change in $N_{\text {act }}$ when the aerosol activation representation was changed (not shown). In case C_accumulation_mar, T_SMOD_mar_acc produces a higher $N_{\text {act }}$ than T_ship_mar_acc for all cooling rates (Fig. 2a marine), with a similar pattern being applicable to the clean continental and urban environments (Fig. 2b and c). As the SMOD scheme for these tests assumes non-adiabatic cooling exclusively, the increase in $N_{\text {act }}$ is due to the associated thermodynamical function being independent of adiabatic lifting and hence a change in pressure (see Appendix A for further details). Therefore, this demonstrates the dependency on the total number of activated aerosols on how the cooling is applied. To understand the impact of a $w_{\min }$ threshold on $N_{\text {act }}$, all tests using the Shipway activation scheme were rerun, with the $w_{\text {min }}$ threshold of $0.1 \mathrm{~m} \mathrm{~s}^{-1}$ being applied (Tests T_ship_mar_acc_wmin, T_ship_con_acc_wmin and T_ship_urb_acc_wmin). Applying this threshold resulted in a fixed $N_{\text {act }}$ for a cooling rate below $3.51 \mathrm{~K} \mathrm{~h}^{-1}$. Consequently, should there be a cooling rate lower than this threshold, $N_{\text {act }}$ will be overestimated, and this may impact properties of the fog evolution such as the fog's optical depth.

Figure 2d, e and f show the percentage difference between the SMOD and Shipway (with an applied $w_{\min }$ ) activation schemes increases as the prescribed cooling rate decreases. When comparing the three environments, the rate of increase in the percentage difference grows, as the tested environment becomes more polluted. For example, a cooling rate of $1.5 \mathrm{~K} \mathrm{~h}^{-1}$ results in a percentage difference of $40 \%, 50 \%$ and $70 \%$ for the three environments respectively. Given the associated percentage difference, this indicates aerosol activation in fog simulations is overestimating $N_{\text {act }}$ by an appreciable amount. However, reducing the minimum threshold, $w_{\text {min }}$, to give an equivalent cooling rate close to those observed in fog would reduce but not remove the problem associated with the percentage difference. Between the SMOD and Shipway schemes for aerosols in the accumulation mode, the associated percentage change ranges between $-10 \%$ and $-20 \%$ for all three environments, and the rate of change in the percentage difference is not appreciably different for any given environment (Fig. 2d, e and f). This implies that even if the minimum threshold of $w_{\text {min }}$ were to be reduced such that it is representative for updraught velocities found in radiation fog, just using the Shipway scheme could potentially underestimate aerosol activation.

\section{Testing Shipway and SMOD schemes using MONC}

The offline box model results demonstrate that assumptions widely used in aerosol activation (e.g. Abdul-Razzak and Ghan, 2000) may be significantly overestimating aerosol activation in fog. This section will investigate the impact that aerosol activation representation will have on fog evolution, using the Met Office Natural Environment Research Council Cloud (MONC) model (Brown et al., 2015, 2018). MONC is a large-eddy simulation model designed to research and develop parameterisations used in the forecast model. MONC and has the same equation set as the older Met Office Large Eddy Model (LEM; Gray et al., 2001), and unlike the LEM, MONC has been designed to couple with other modules, including the Cloud AeroSol Interactive Microphysics scheme (CASIM; Grosvenor et al., 2017; Miltenberger et al., 2018) and the Suite of Community Radiative Transfer codes (SOCRATES; Edwards and Slingo, 1996). MONC is widely used in the UK atmospheric science community and has been used to study atmospheric processes in low-level clouds in West Africa (Dearden et al., 2018), fog (Poku et al., 2019) and idealised convection simulations (Böing et al., 2019).

\subsection{MONC model - online setup}

As part of this work, MONC is used to perform a suite of sensitivity tests based on intensive observation period 1 (IOP1) from the recent Local And Non-local Fog EXperiment (LANFEX) field campaign (Price et al., 2018). A full description of IOP1 and the observed vertical profiles the model was initialised with can be found in Poku et al. (2019). The model setup for IOP1 is presented in Table 4. A domain size of $132 \times 132 \mathrm{~m}^{2}$ was chosen, as there is minimal impact on the fog's turbulent kinetic energy (TKE) and liquid water when compared to simulations that were tested on a larger domain (not shown). Although previous studies such as Maalick et al. (2016) and Maronga and Bosveld (2017) have run LES fog simulations at higher horizontal resolutions, we found that running our cases at $2 \mathrm{~m}$ allowed for us to address our objectives whilst compromising on both data storage and computational expense (not shown). The model's surface boundary conditions were prescribed with a varying surface temperature (described in Poku et al., 2019) and a surface vapour mixing ratio of $0.004 \mathrm{~kg} \mathrm{~kg}^{-1}$, which were both based on observations. Radiation was calculated 

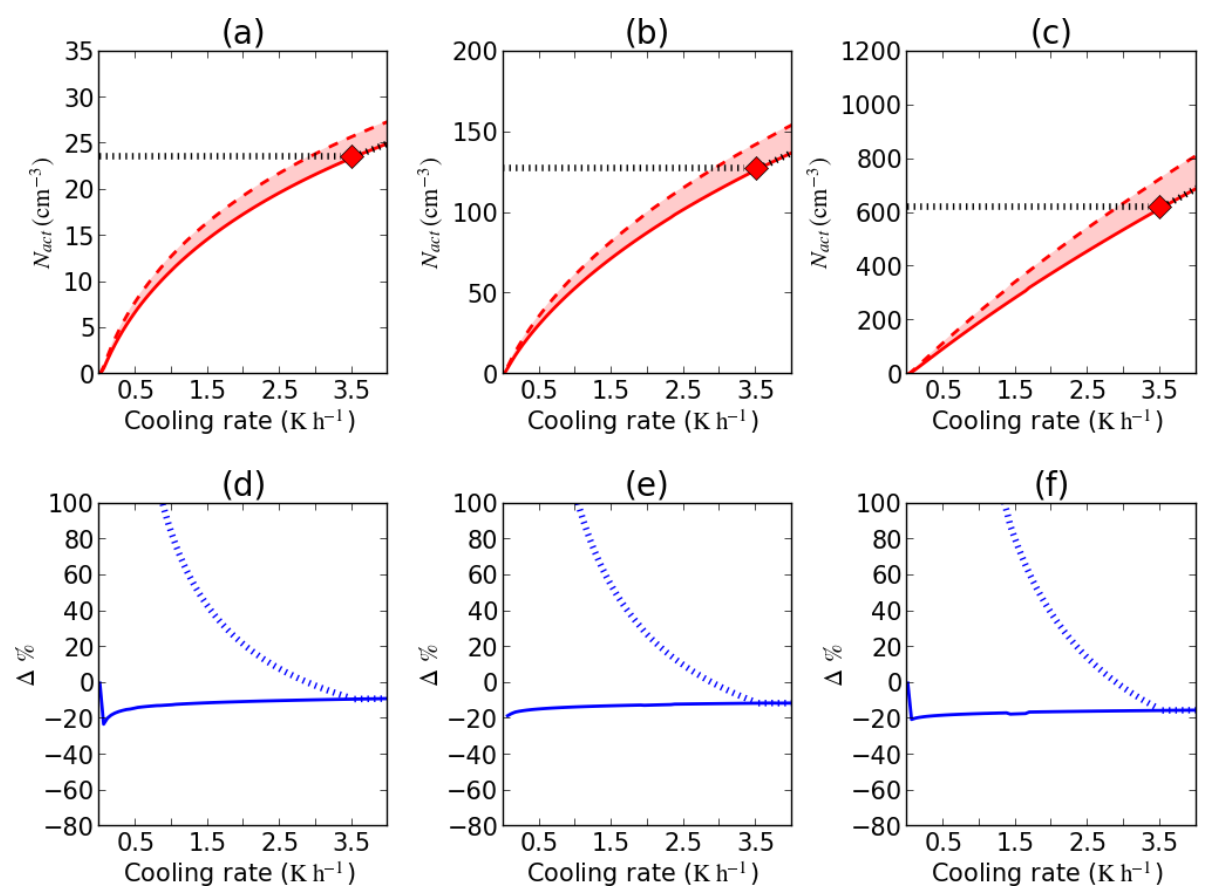

Figure 2. (a) Total activated aerosols, $N_{\text {act }}$, against the cooling rate for marine environment accumulation-mode aerosols. Solid line T_ship_mar_acc; dashed line - T_SMOD_mar_acc; black dashed line - T_ship_mar_acc_wmin. (d) Percentage differences, $\Delta \%$, between the following: dashed line - T_ship_mar_acc against T_ship_mar_acc_wmin; solid line - T_ship_mar_acc against T_SMOD_mar_acc. Red diamond $-w_{\min }=0.1 \mathrm{~m} \mathrm{~s}^{-1} ;(\mathbf{b}, \mathbf{e})$ clean continental; $(\mathbf{c}, \mathbf{f})$ urban.

Table 4. The input parameters and model setup for IOP1 in MONC.

\begin{tabular}{ll}
\hline IOP1 input parameters & Values \\
\hline Horizontal domain & $132 \times 132 \mathrm{~m}$ \\
Vertical domain & $705 \mathrm{~m}$ \\
$\Delta x, \Delta y$ & $2 \mathrm{~m}$ \\
$\Delta z$ & $1 \mathrm{~m}$ for first $100 \mathrm{~m}$ of vertical domain, stretched to $6 \mathrm{~m}$ from $100 \mathrm{~m}$ to top of vertical domain \\
Simulation duration & $12 \mathrm{~h}$ \\
Time step & $0.1 \mathrm{~s}$ \\
Surface geostrophic winds & $u_{\mathrm{g}}=1.3, v_{\mathrm{g}}=2.1 \mathrm{~m} \mathrm{~s}^{-1}$ \\
Cloud microphysics & Cloud AeroSol Interactive Microphysics (CASIM) \\
Radiative transfer scheme & Suite of Community Radiative Transfer codes (SOCRATES) (Edwards and Slingo, 1996) \\
\hline
\end{tabular}

using SOCRATES based on the work of Edwards and Slingo (1996). SOCRATES was called by the MONC model every $30 \mathrm{~s}$, allowing for the longwave radiative fluxes at the top of the fog layer to be captured in the model.

All simulations use the CASIM scheme - a multi-moment bulk microphysics scheme designed to simulate aerosolcloud interactions (Grosvenor et al., 2017; Dearden et al., 2018; Miltenberger et al., 2018). For this work, CASIM has been set to two moments and is being used to represent a non-precipitating, warm boundary layer cloud (i.e. ice processes and autoconversion to rain are turned off). In CASIM, the cloud-drop size distribution, $N(D)$, assumes a gamma distribution, which has the form (Shipway and Hill, 2012)

$N(D)=N_{0} D^{\mu_{\mathrm{d}}} e^{-\lambda_{\mathrm{d}} D}$,

where $N_{0}$ is the distribution intercept parameter, $\mu_{\mathrm{d}}$ is the shape parameter (the default value of $\mu_{\mathrm{d}}$ is set to 0 ), $\lambda_{\mathrm{d}}$ is the slope parameter and $D$ is the droplet diameter. For this work, $\mu_{\mathrm{d}}$ has been set to equal 3.0, based on observations of the liquid water path (LWP) and cloud-drop size distribution during IOP1, resulting in a more sensible modelled sedimentation rate (see Appendix B for details).

During IOP1, there were no direct aerosol or CCN measurements. Therefore, we initially planned to use a multi-mode lognormal aerosol distribution of $1000 \mathrm{~cm}^{-3}$ Aitken-mode aerosols (mean diameter $0.05 \mu \mathrm{m}$ ), $100 \mathrm{~cm}^{-3}$ 
accumulation-mode aerosols (mean diameter $0.15 \mu \mathrm{m}$ ) and $2 \mathrm{~cm}^{-3}$ coarse-mode aerosols (mean diameter $1 \mu \mathrm{m}$ ), each following a standard deviation of 2.0, as proposed and used in Boutle et al. (2018). Using these values would therefore be representative of the clean air typically found at Cardington. However, our simulations used a single accumulation aerosol mode to maintain consistency with the tests in the Shipway box model, which showed that when considering aerosol activation, the activated $N_{\mathrm{a}}$ for IOP1 can be accounted for by accumulation-mode aerosols (not shown). A consequence of assuming a single accumulation mode potentially limits droplet concentration overestimation, which would lead to the fog layer transitioning too quickly in optical thickness. However, based on our offline test results, we believe that using a multi-mode aerosol spectrum would have led to an unnecessary computational expense in this study. This reasoning may be different should these simulations have been run with a prognostic for supersaturation, but this is outside the scope of this work. To reduce computational expense and data storage, $1 \mathrm{D}$ diagnostics are output every $1 \mathrm{~min}$ and $3 \mathrm{D}$ diagnostics are output every $5 \mathrm{~min}$.

SMOD was implemented into MONC based on Eq. (9), which involves adding the adiabatic and non-adiabatic contributions together for the combined cooling rate to them be used for aerosol activation. The adiabatic contribution for this equation was derived from the resolved positive updraught velocity in MONC. The non-adiabatic contribution to date only consists of the longwave heating tendency that is derived using SOCRATES. For reference, the implementation of these partitioned terms is done similarly to the aerosol activation scheme used by Vie et al. (2016). Although it has been acknowledged that there are other non-adiabatic contributions to changes in supersaturation such as turbulent mixing, further model development would be required to account for these changes. However, given that radiative cooling is the biggest source of saturation during fog formation (Roach et al., 1976), these results should provide useful insight into the representation of aerosol activation during a stable fog case.

Table 5 displays all tests that will evaluate Shipway against SMOD. The first objective will be addressed by comparing tests T1-T3, and the outcome of this comparison will improve the understanding of how different activation representations could influence the fog droplet number concentration (FDNC) evolution in IOP1. To date, the effective radius, $r_{\mathrm{e}}$, has the option to be fixed or for it to vary with a change in FDNC. To isolate the impact of aerosol activation on number concentration, this work used a fixed $r_{\mathrm{e}}$. As the non-adiabatic contribution in the SMOD scheme is directly influenced by $r_{\mathrm{e}}$, two tests were set up to test its sensitivity and hence will motivate future work that involves deciding whether a coupled effective radius is required when using the SMOD scheme.

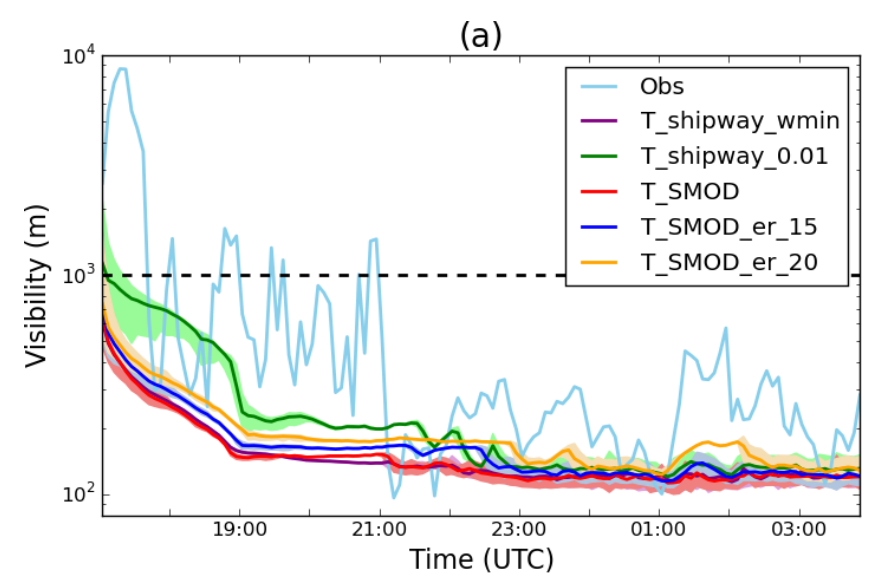

(b)

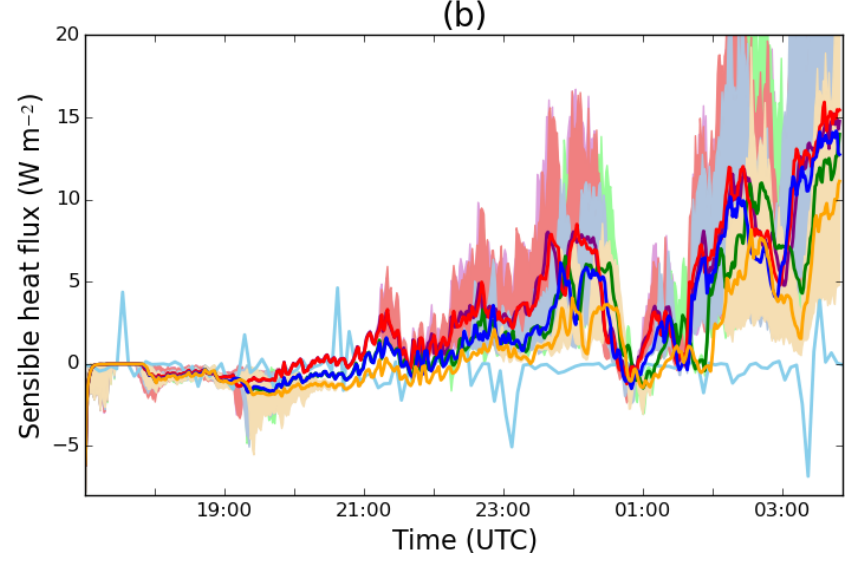

Figure 3. (a) Time series of the near-surface mean visibility (Vis; $\mathrm{m})$ at a $2 \mathrm{~m}$ altitude. Purple - T_shipway_wmin; green T_shipway_0.01; red - T_SMOD; blue - T_SMOD_er_15; orange - T_SMOD_er_20; light blue - observations. (b) Time series of the surface sensible heat flux $\left(\mathrm{W} \mathrm{m}^{-2}\right)$. Purple - T_shipway_wmin; green - T_shipway_0.01; red - T_SMOD; blue - T_SMOD_er_15; orange - T_SMOD_er_20; light blue - observations. Minimum and maximum (a) visibility and (b) sensible heat flux are marked on the figure by the shaded area.

\subsection{Comparing simulations using the Shipway and SMOD schemes}

Fog forms in tests T_shipway_wmin, T_shipway_0.01 and T_SMOD at 17:00 UTC, and all decrease to a mean nearsurface visibility of $120 \mathrm{~m}$ by the end of the night (Fig. 3a). For all model simulations, visibility, Vis, is calculated using the formula of Gultepe et al. (2006):

Vis $=\frac{1.002}{(\mathrm{LWC} \times \mathrm{FDNC})^{0.6473}}$,

where LWC is the liquid water content and FDNC is the fog droplet number concentration. Equation (12) was derived based on observations of fog in mainland Europe and is valid over a range of droplet concentrations from a few per cubic 
Table 5. Details of the simulations using the Shipway and SMOD activation scheme. The value of $w_{\text {min }}$ has been lowered from 0.1 to $0.01 \mathrm{~m} \mathrm{~s}^{-1}$ based on the results from Sect. 4 . The cooling rate equivalent is calculated using the dry adiabatic lapse rate assumption. For SMOD, imposing a $w_{\min }$ was not applicable (n/a).

\begin{tabular}{lllllr}
\hline Test number & Test name & Scheme & $\begin{array}{l}\text { Imposed } w_{\text {min }} \\
\left(\mathrm{m} \mathrm{s}^{-1}\right)\end{array}$ & $\begin{array}{l}\text { Threshold cooling rate } \\
\text { equivalent }\left(\mathrm{K} \mathrm{h}^{-1}\right)\end{array}$ & $\begin{array}{c}r_{\mathrm{e}} \\
(\mu \mathrm{m})\end{array}$ \\
\hline T1 & T_shipway_wmin & Shipway & 0.1 & 3.51 & 10 \\
T2 & T_shipway_0.01 & Shipway & 0.01 & 0.351 & 10 \\
T3 & T_SMOD & SMOD & n/a & n/a & 10 \\
T4 & T_SMOD_er_15 & SMOD & n/a & n/a & 15 \\
T5 & T_SMOD_er_20 & SMOD & n/a & n/a & 20 \\
\hline
\end{tabular}

centimetre up to a few hundred per cubic centimetre (Gultepe et al., 2006).

Despite the differences in near-surface visibility, all three tests have the strongest rate of decrease between 17:00 and 18:45 UTC (Fig. 3a). During this time, the mean nearsurface visibility in T_shipway_wmin, T_shipway_0.01 and T_SMOD decreases to 208,151 and $210 \mathrm{~m}$ respectively. T_shipway_0.01 has a noticeably higher near-surface visibility before 18:30 UTC and best agrees with observations, before decreasing in visibility at the same rate as T_shipway_wmin. Upon first inspection, it appears that just lowering $w_{\min }$ is the solution to prevent the simulation overestimating aerosol activation in fog, as shown by T_shipway_0.01. However, the model's spin-up period lasted around an hour in these simulations, meaning that the FDNC calculation is likely being influenced by initial prescribed random perturbations, as opposed to turbulence driven by either wind shear or convective motion. Unfortunately, with the earliest radiosonde data available being at 17:00 UTC, the features in T_shipway_0.01 could not be avoided (for context, the observations show a stable boundary layer (SBL) beginning to form around the time of model initialisation). Nonetheless, the lower threshold used in T_shipway_0.01 allows for the simulation to undergo a slower transition in near-surface visibility to a thicker fog. This suggests that the number of activated droplets calculated may account for an inaccurate representation of what was observed during IOP1.

Up until 21:00 UTC, T_shipway_wmin and T_SMOD and T_shipway_0.01 mostly experience a zero or slightly negative sensible heat flux (SHF), which agrees well with observations (Fig. 3b). After 21:00 UTC, all three simulations grow positively in SHF, with both T_shipway_wmin and T_SMOD experiencing two distinct maxima of 6 and $14 \mathrm{~W} \mathrm{~ms}^{-2}$ at times 00:00 and 04:00 UTC respectively. A mostly positive SHF is due to the fog layer growing enough in both depth and optical thickness that it will begin to warm the surface (Price, 2011). As the observed SHF was mostly zero throughout the night, our results indicate that the default $w_{\min }$ used in the Shipway scheme will lead to the fog episode transitioning to a well-mixed layer too quickly. Up until 01:00 UTC, T_shipway_0.01 has a lower SHF than
Table 6. Ratio of modelled to observed cloud drop number averaged over the vertical height across tested time frames (3 significant figures (sf)).

\begin{tabular}{lrrr}
\hline Test name & 22:30 UTC & 00:30 UTC & 03:30 UTC \\
\hline T_shipway_wmin & 2.77 & 1.66 & 2.99 \\
T_shipway_0.01 & 2.54 & 1.69 & 2.96 \\
T_SMOD & 3.03 & 1.70 & 3.07 \\
T_SMOD_er_15 & 2.78 & 1.65 & 3.00 \\
T_SMOD_er_20 & 2.63 & 1.59 & 2.92 \\
\hline
\end{tabular}

T_shipway_wmin and T_SMOD, despite it remaining positive. This result highlights the inaccuracy of simulating fog cases with just an updraught velocity, providing further evidence for the use of the SMOD scheme. However, despite this suggestion, T_SMOD in its default settings is performing worse than T_shipway_0.01. This discrepancy will be discussed further in Sect. 5.2.1 of this paper. There is a possibility that the simulated SHF results may have some uncertainty due to no land-surface scheme being coupled to MONC to date, which has been shown to be important when the fog becomes optically thick (e.g. Porson et al., 2011). Unfortunately, investigating this uncertainty is outside the scope of this work.

Vertical profiles of observed fog droplet number concentration (FDNC) initially show spatial variation throughout the layer, where it begins to homogenise throughout the night (Fig. 4). At 00:30 UTC, it appears as though the fog layer decreased in height. However, this feature is most likely due to an instrumentation limitation, resulting in only accounting for cloud droplets that were of sizes between 2 and $40 \mu \mathrm{m}$ in diameter, with a $1 \mu \mathrm{m}$ uncertainty (Price et al., 2018). Therefore, there is a probability that droplets that have begun growing through condensation were not accounted for. Within the fog layer, T_shipway_wmin and T_SMOD both have an activation rate between $75 \%-80 \%$, which increases to around $90 \%$ later in the night. Furthermore, the modelled to observed fog droplets for both simulations are 2.77 and 3.03 respectively (Table 6 ). Consequently, both the simulated activation and proportion rates lead to the fog layer grow- 

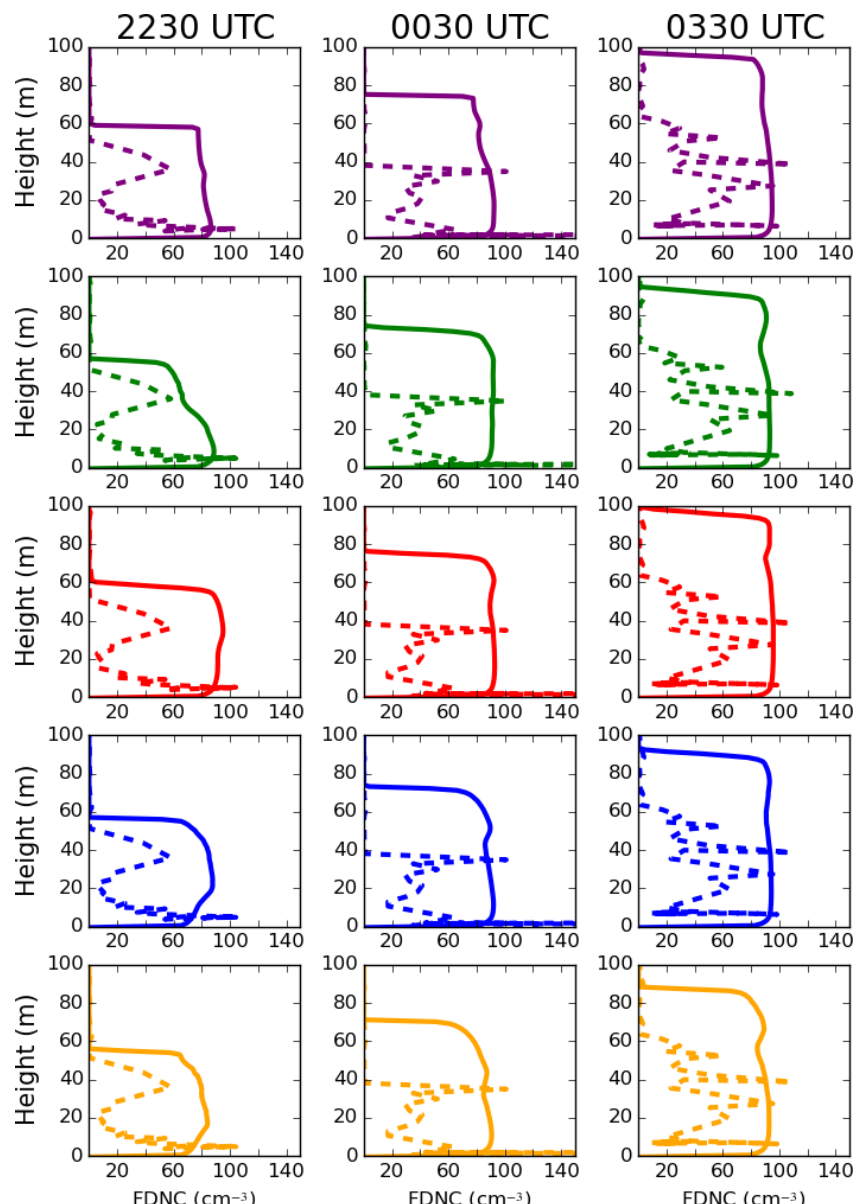

Figure 4. Vertical profiles of the fog droplet number concentration $\left(\mathrm{cm}^{-3}\right)$ at 22:30, 00:30 and 03:30 UTC. The dashed lines represent observations, and solid lines represent simulated values. Purple T_shipway_wmin; green - T_shipway_0.01; red - T_SMOD; blue - T_SMOD_er_15; orange - T_SMOD_er_20.

ing $40 \mathrm{~m}$ too deep in comparison to observations. Initially, T_shipway_0.01 has the lowest droplet proportion rate, with the simulated spatial vertical FDNC agreeing best with observations. However, it begins to have activation and proportion rates similar to T_shipway_wmin and T_SMOD. This result suggests that the T_shipway_0.01 transition rate to a thicker fog is still too fast, indicating that using an activation scheme driven by just an updraught velocity is unsuitable for fog simulations.

Throughout the night, both T_shipway_wmin and T_SMOD have a higher LWP than T_shipway_0.01 (Fig. 5). Poku et al. (2019) showed that the LWP increases with aerosol concentration and hence FDNC, with Porson et al. (2011) demonstrating that the increase in FDNC resulted in a stronger downwelling longwave flux, signalling the presence of a deeper fog. T_shipway_wmin has the steepest decrease in visibility during fog formation, suggesting that it has the highest initial FDNC. As these tests all have the same

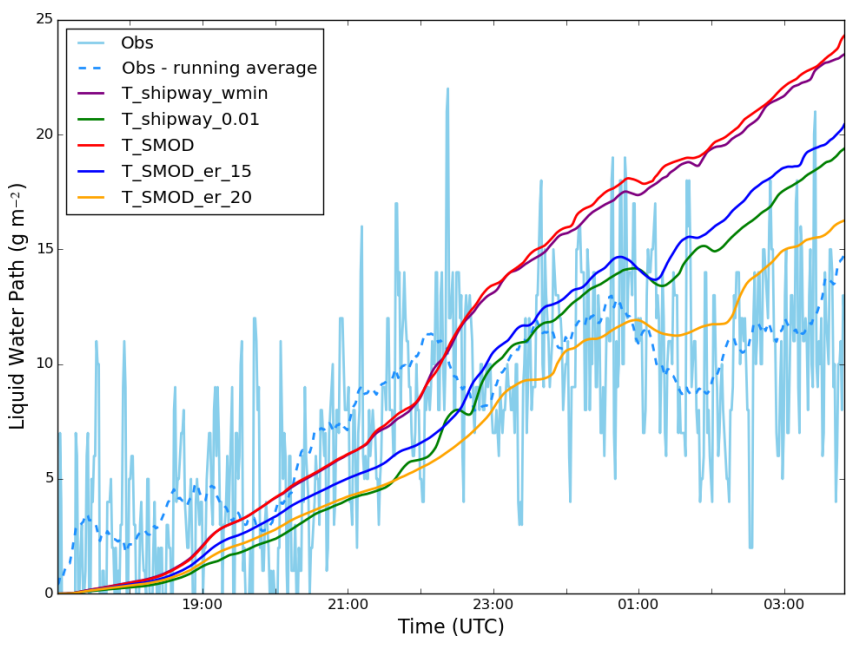

Figure 5. (a) Time series of the surface deposition rate $\left(\mathrm{g} \mathrm{m}^{-2} \mathrm{~h}^{-1}\right)$. Purple - T_shipway_wmin; green - T_shipway_0.01; red - T_SMOD; blue - T_SMOD_er_15; orange T_SMOD_er_20; light blue - observations. (b) Time series of the liquid water path $\left(\mathrm{g} \mathrm{m}^{-2}\right)$. Purple - T_shipway_wmin; green - T_shipway_0.01; red - T_SMOD; blue - T_SMOD_er_15; orange - T_SMOD_er_20; light blue - observations; blue dashed line - running average over observations (40 points).

fixed effective radius (unlike studies such as Stolaki et al., 2015), the change in LWP is primarily due to the sedimentation rate, therefore indicating that $\mathrm{T}$ _shipway_wmin has the slowest sedimentation rate of all three tests as a result. A decreased sedimentation rate will lead to more liquid water being present in the fog layer. Consequently, this will lead to stronger cooling at the fog top (Poku et al., 2019), strengthening the feedback of increased liquid water production in the layer. This result provides further evidence of how the error in aerosol activation that utilises a $w_{\min }$ of $0.1 \mathrm{~m} \mathrm{~s}^{-1}$ impacts the fog, especially during the initial formation stage. The LWP and mean near-surface visibility are not appreciably different between T_shipway_wmin and T_SMOD (Fig. 5), suggesting the FDNC is very similar between the two. T_shipway_0.01 has the highest near-surface visibility between 17:00 and 23:00 UTC by up to $340 \mathrm{~m}$, in addition to the lowest LWP by up to $4 \mathrm{~g} \mathrm{~m}^{-2}$. Averaged time-height slices of FDNC and LWC were taken for all three tests, showing relatively small changes in the fog layer's FDNC between T_shipway_wmin and T_SMOD (not shown).

So far we have seen that T_SMOD is performing similar to T_shipway_wmin, with T_shipway_0.01 appearing to be the ideal solution for simulating IOP1. However, this may indicate that the default settings for SMOD may not be suitable for our study. The similarity of T_shipway_wmin and T_SMOD suggests that the combined cooling rate in T_SMOD is similar to the cooling rate associated with $w_{\mathrm{min}}$ in T_shipway_wmin. To understand whether this is the case, a horizontal slice at $z=2 \mathrm{~m}$ of FDNC and the contributions 
17:30 UTC 19:00 UTC 21:00 UTC 01:00 UTC

(a)

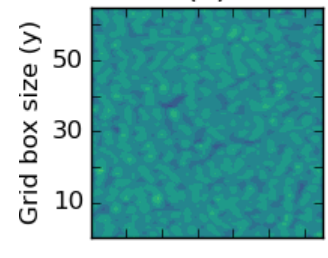

(e)

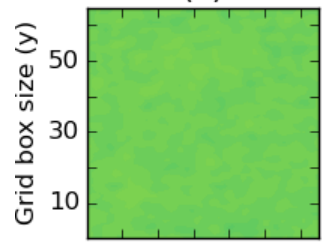

(i)

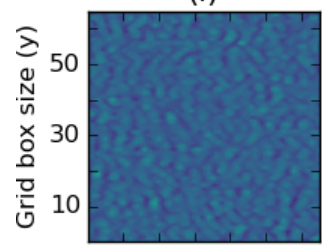

(m)

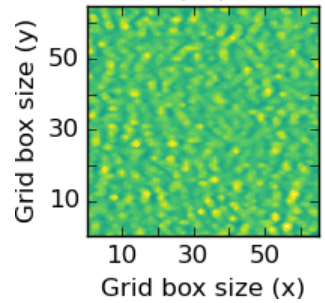

(b)

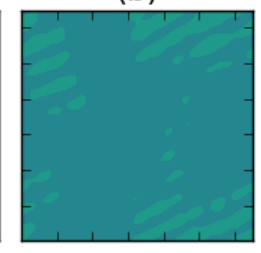

(f)

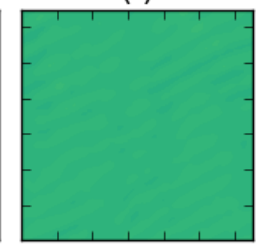

(j)

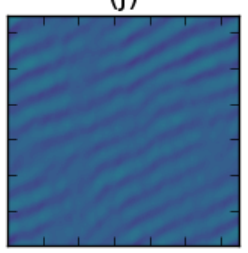

(n)

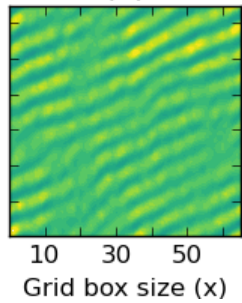

(c)

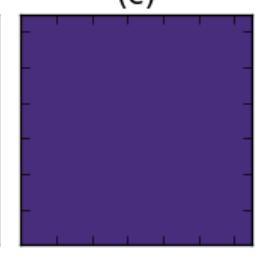

(g)

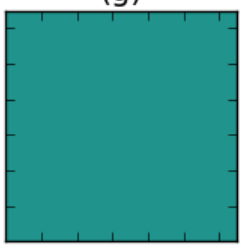

(k)

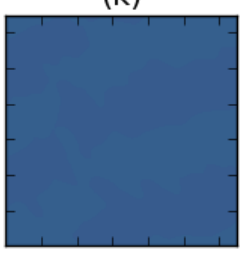

(o)

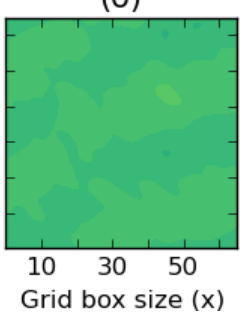

(d)

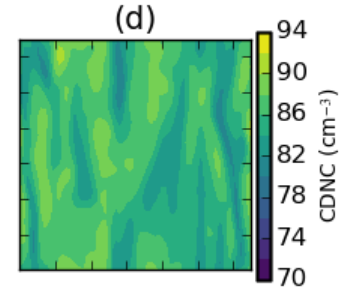

(h)

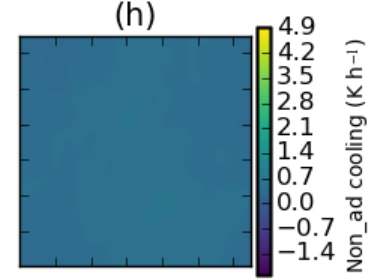

(I)

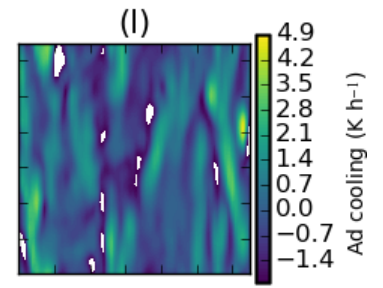

(p)

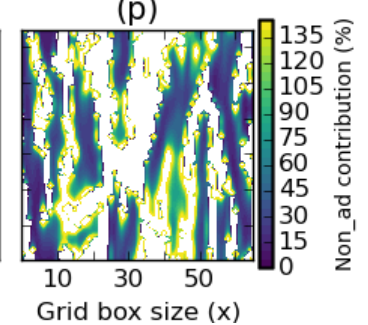

Figure 6. Horizontal slices made at $z=2 \mathrm{~m}$ of FDNC $\left(\mathrm{cm}^{-3}\right)$ in T_SMOD at (a) 17:30, (b) 19:00, (c) 21:00 and (d) 01:00 UTC. (e-h) Non-adiabatic cooling $\left(\mathrm{K} \mathrm{h}^{-1}\right)$; (i-l) adiabatic cooling $\left(\mathrm{Kh}^{-1}\right)$; $(\mathbf{m}-\mathbf{p})$ non-adiabatic cooling contribution $(\%)$. Note that for the cooling contribution, white masks out regions where the contribution is greater than $140(\%)$.

to the relative cooling rates were taken at different times, as shown in Fig. 6. As $2 \mathrm{~m}$ is not at the model's lowest vertical grid box, there should not be any direct heating from the imposed surface conditions. At 17:30 UTC the FDNC is about $83 \mathrm{~cm}^{-3}$ (Fig. 6a), with more than $85 \%$ of the total cooling contribution being due to longwave heating (Fig. 6m). However, later in the night, the cooling contribution to longwave tendencies increases to around $90 \%$ within the fog layer (Fig. 6o), due to a decrease in the adiabatic cooling tendency to about $0.5 \mathrm{~K} \mathrm{~h}^{-1}$ (Fig. 6k). Eventually, the fog develops, resulting in the longwave contribution to cooling decreasing to around $15 \%$ (Fig. 6p), with an increase in cooling due to vertical motion. The drop in near-surface longwave cooling occurs as the fog transitions to become optically thick, and so the longwave flux divergence becomes smaller near the surface, while the adiabatic effects become larger due to the onset of convection driven by radiative cooling at the fog top (Mazoyer et al., 2017).
The new SMOD activation scheme is more physically realistic in that it is coupled to the radiative cooling in the fog, making the scheme potentially more sensitive to the way that this cooling is calculated in the model. Therefore, the assumption of the effective radius being fixed for these simulations may not be suitable to accurately simulate the radiative impact of the fog layer. The following section will present some sensitivity tests to assess the impact of this assumption on fog development.

\subsubsection{Sensitivity of SMOD to the effective radius}

Hill et al. (2008) showed the impact of using a fixed effective radius on stratocumulus cloud simulations, with studies such as Bierwirth et al. (2013) and Young et al. (2016) showing how the observed effective radius in arctic clouds can change (between 5 and $15 \mu \mathrm{m}$ ) in relation to the cloud's LWC and FDNC. As this variability may be key to modelling radiation 
fog using the SMOD activation scheme, two tests were conducted that investigated the fog's sensitivity to a change in $r_{\mathrm{e}}$.

When increasing $r_{\mathrm{e}}$ from 10 to $20 \mu \mathrm{m}$, the near-surface visibility increases by up to $40 \%$ and decreases the LWP by up to $42 \%$ (Fig. 3a). Furthermore, increasing $r_{\mathrm{e}}$ leads to the simulated SHF better agreeing with observations, despite it still being positive later in the night (Fig. 3b). However, although increasing $r_{\mathrm{e}}$ results in the LWP agreeing better with observations (Fig. 5), neither test captures the changes in near-surface visibility during fog formation (Fig. 3b). Previous studies (e.g. Bergot et al., 2015; Ducongé et al., 2020) argued that it is critical to account for a heterogeneous terrain when simulating the fog's initial spatial variability. However, Cardington is relatively homogeneous and hence potentially highlights a further discrepancy in the aerosol representation in these simulations. As an example, in-cloud removal (nucleation scavenging) has not been accounted for in this work, which has been shown to impact the spatial variability and development of mixed-phased clouds (Miltenberger et al., 2018). In addition, the discrepancy in our results may be due to these simulations utilising a bulk microphysics scheme, which has been shown to not account for hydrated and small newly formed droplets (Schwenkel and Maronga, 2020). Nonetheless, the decrease in liquid water indicates that the fog's development in optical thickness has slowed down with an increase in $r_{\mathrm{e}}$ and hence the importance of coupling both CASIM and SOCRATES together. Going forward, future studies should use a coupled $r_{\mathrm{e}}$ as this should, in theory, lead to an improvement in FDNC as the better representation in aerosol activation in the SMOD scheme will feed into the radiation scheme.

Figure 7 shows time-height slices of FDNC and LWC for T_SMOD, T_SMOD_er_15 and T_SMOD_er_20. Before 21:45 UTC, the FDNC in T_SMOD is strongest towards the top at around $80 \mathrm{~cm}^{-3}$. After this time, it increases throughout the fog layer to a range between 86 and $94 \mathrm{~cm}^{-3}$ (Fig. 7a). These changes in FDNC can be noted when compared to observations, where both T_SMOD_er_15 and T_SMOD_er_20 begin to have a less uniform structure throughout the fog layer (Fig. 4). Coinciding with this is an increase in LWC from 0.2 to $0.24 \mathrm{~g} \mathrm{~kg}^{-1}$, suggesting the time at which the fog began to develop and grow in optical thickness. However, an increase in $r_{\mathrm{e}}$ results in delayed onset of the growth in optical thickness to 23:00 and 00:30 UTC for T_SMOD_er_15 and T_SMOD_er_20 respectively. The FDNC on average decreases for both T_SMOD_er_15 and T_SMOD_er_20 across the whole fog layer, with a noticeable rise at around 23:00UTC for T_SMOD_er_15. Although this pattern is the same for T_SMOD_er_20, there are periods where there are visible decreases in FDNC, e.g. between 01:30 and 02:30 UTC (Fig. 7c and e respectively). A combination of both the FDNC and LWC decreasing results in a slower transition in the fog layer, which is shown in the downwelling longwave at $2 \mathrm{~m}$ (Fig. 8). The downwelling longwave decreases by a maximum of $20 \mathrm{~W} \mathrm{~m}^{-2}$ between
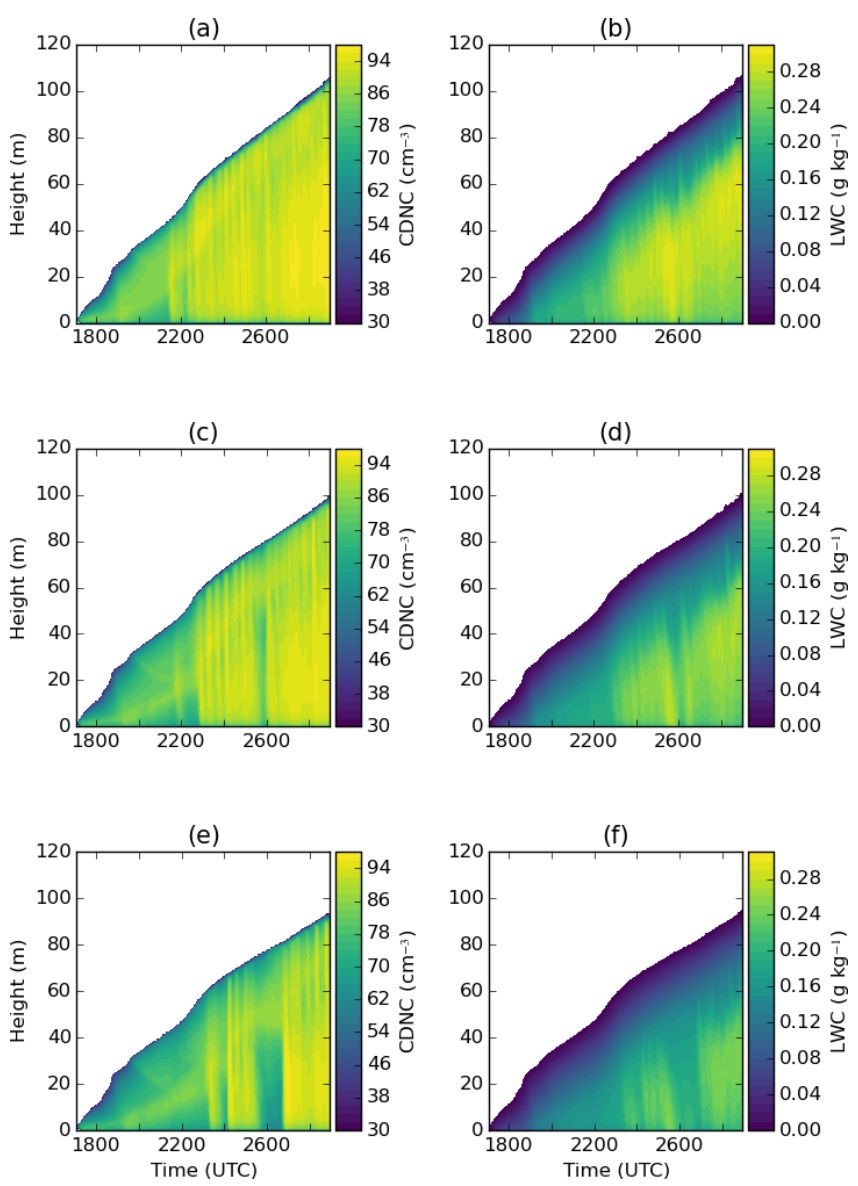

Figure 7. Plots of panels (a), (c) and (e) show the average FDNC $\left(\mathrm{cm}^{-3}\right)$; and panels (b), (d) and (f) show the average LWC $\left(\mathrm{g} \mathrm{kg}^{-1}\right)$. Panels (a) and (b) show T_SMOD; panels (c) and (d) show T_SMOD_er_15; panels (e) and (f) show T_SMOD_er_20.

T_SMOD and T_SMOD_er_20, with T_SMOD_er_20 undergoing the slowest positive rate with all the simulations presented in this paper. There are differences between the observed and simulated downwelling in all three simulations; however, before 22:00 UTC, T_SMOD_er_20 decreases this difference to a maximum of $10 \mathrm{~W} \mathrm{~m}^{-2}$.

SOCRATES calculates the longwave radiative fluxes by the cloud's optical depth, $\tau$ (Edwards and Slingo, 1996):

$\tau=k^{(\mathrm{e})} \Delta m$,

such that $\Delta m$ is the change in mass for a given spectral band, and $k^{(\mathrm{e})}$ is the mass extinction coefficient, which is defined as

$k^{(\mathrm{e})}=L\left(a+\frac{b}{r_{\mathrm{e}}}\right)$.

For the SMOD scheme, both the FDNC and LWC is sensitive to $r_{\mathrm{e}}$, given Eqs. (13) and (14). This leads to a more physical representation of aerosol activation that should be considered when simulating cases of fog. These results demonstrate the importance of an accurate effective radius and the 


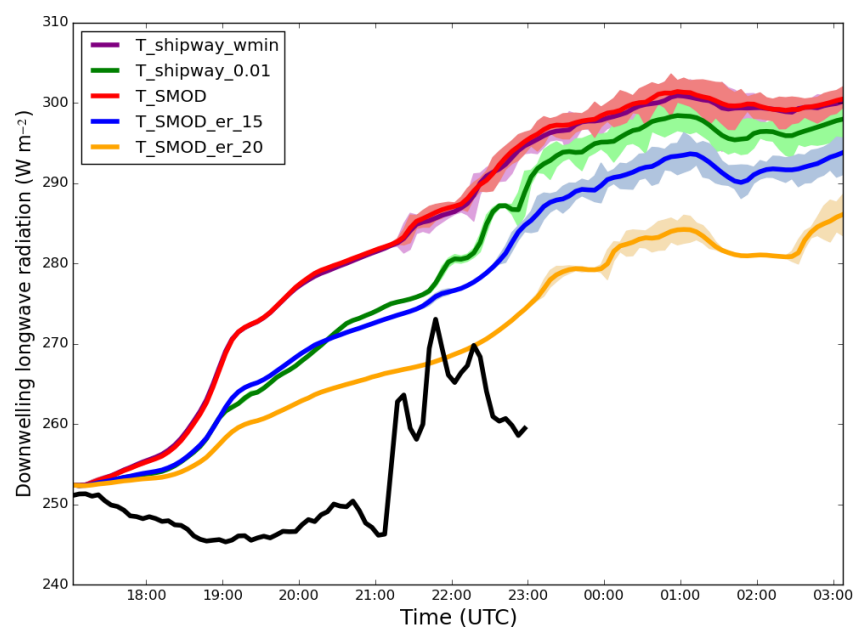

Figure 8. Time series of the downwelling longwave radiation $\left(\mathrm{W} \mathrm{m}^{-2}\right)$ at a $2 \mathrm{~m}$ altitude. Purple - T_shipway_wmin; green T_shipway_0.01; red - T_SMOD; blue - T_SMOD_er_15; orange - T_SMOD_er_20; black - observations. The minimum and maximum downwelling longwave radiation are marked on the figure by the shaded area.

reasons for using a coupled $r_{\mathrm{e}}$, given its impact on the fog evolution.

\section{Discussion}

This work aimed to investigate how the representation of aerosol activation influenced nocturnal radiation fog simulations. There was a strong focus on critiquing the assumptions used in several current aerosol activation schemes, which are usually designed for clouds where cooling is driven by adiabatic ascent. This work addressed two research questions.

\subsection{What are the potential differences in aerosol activation between the Shipway and SMOD scheme?}

The assumptions used in the Shipway (2015) scheme to date, i.e. the use of just an updraught velocity with a minimum threshold $w_{\min }$, were tested against the SMOD scheme in an offline box model. The sensitivity of Shipway to $w_{\text {min }}$ was first tested. For accumulation- and coarse-mode aerosol, there was a monotonic decrease in $N_{\text {act }}$ as $w_{\min }$ approached $0 \mathrm{~m} \mathrm{~s}^{-1}$. These tests also highlighted the stepwise function present in Aitken-mode aerosol in the low-updraughtvelocity regime. Given the fraction of Aitken aerosols activated, our results may suggest that Aitken-mode aerosol can be ignored when modelling activation in fog based on the range of environmental aerosol size distributions, as the required environmental supersaturation for impact is substantially higher than supersaturations seen in reality. However, the stepwise behaviour was caused by the poor resolution in the lookup table that calculated $s_{\max }$ in this regime, there- fore demonstrating why just removing $w_{\min }$ with no alternative cooling source may not be an appropriate solution when simulating aerosol activation in fog.

For accumulation-mode aerosol, there were noticeable percentage differences between the actual cooling rate and the use of a $w_{\min }$ equal to $0.1 \mathrm{~m} \mathrm{~s}^{-1}$ (as typically used in clouds) by up to $70 \%$, as the environment becomes more polluted. In reality, for a given liquid water path, increasing the aerosol concentration will result in a larger concentration of smaller droplets, increasing the fog's optical depth (Twomey, 1977), and may cause the fog to become well mixed too quickly. Therefore for this example, a similar effect could occur should an unsuitable $w_{\min }$ be used in fog simulations. In addition, these tests demonstrated that using an aerosol activation scheme that assumes just adiabatic ascent may potentially underestimate $N_{\text {act }}$ by $20 \%$ in an environment driven by non-adiabatic cooling processes (i.e. fog formation). Furthermore, the associated percentage difference in the choice of $w_{\text {min }}$ would be the same should SMOD be run with just an adiabatic cooling source, given there were no differences in the Shipway and SMOD scheme in an adiabatic setup. Consequently, both of these results show that the aerosol indirect effects may not be properly accounted for in fog simulations when using a traditional aerosol activation scheme.

\subsection{How do the differences in aerosol activation representation impact the fog evolution in a large eddy simulation?}

The Shipway (2015) aerosol activation scheme was used to test the impact $w_{\min }$ could have on simulating fog in MONC using only accumulation-mode aerosol. It was shown that a reduction in $w_{\min }$ lowered the initial FDNC during formation, resulting in the fog undergoing a slower transition to a well-mixed layer. Reducing $w_{\min }$ to $0.01 \mathrm{~m} \mathrm{~s}^{-1}$ displayed some unusual model behaviours during fog formation, which is most likely driven by the model's spin-up period rather than shear or convective motion. However, the only way to confirm this is to initialise the model earlier, which is not possible with the given radiosonde data from IOP1. Upon initial analysis, there was not an improved performance using the SMOD scheme against the Shipway scheme with an applied $w_{\min }$ of $0.1 \mathrm{~m} \mathrm{~s}^{-1}$. A further inspection showed that the cause of this result was due to $r_{\mathrm{e}}$ not reflecting the change in FDNC. When $r_{\mathrm{e}}$ was increased from 10 to $20 \mu \mathrm{m}$, the result was a slower transition to a well-mixed layer, which was more in line with observations of IOP1. This highlighted the importance of the effective radius and provides further motivation to couple the effective radius with a change in FDNC. However, despite this result using the SMOD scheme, our work has highlighted potential physical processes regarding aerosol missing in this study, demonstrating the complexities when simulating aerosol-fog interactions in nocturnal radiation fog. 


\section{Conclusions}

This work has demonstrated the unsuitability of using an aerosol activation scheme designed for convective clouds in fog simulations, complementing previous studies such as Schwenkel and Maronga (2019), who have shown how the choice in aerosol activation scheme impacts the fog evolution through a change in the FDNC. Similar to our study, they and authors such as Mazoyer et al. (2017) have used a similar mathematical framework with their choice in using a non-adiabatic cooling in an aerosol activation scheme first utilised by Zhang et al. (2014). Our work in this paper complements this and other studies by doing the following:

1. Although as suggested by Boutle et al. (2018) that the solution is to remove the $w_{\min }$ threshold when simulating radiation fog, our results show that this is not necessarily a suitable option. This is highlighted with T_shipway_0.01, which although did initially perform better than the rest of the tests discussed, it transitioned quicker to a thicker fog than both T_SMOD_er_15 and T_SMOD_er_20. As aerosol activation in T_shipway_0.01 was driven by just an updraught velocity, this suggests why a more physically based activation scheme such as SMOD is critical to simulate nocturnal radiation fog. More specifically, the choice in activation scheme is key when the fog layer may transition to an optically thick layer.

2. Although there have been studies investigating the use of the non-adiabatic framework in fog simulations, this is the first study to the author's knowledge that critiques this framework with a fog case that formed in clean aerosol regimes (accumulation $\mathrm{CCN}<100 \mathrm{~cm}^{-3}$ as defined by Boutle et al., 2018), therefore supporting previous literature on the topic of aerosol-fog interactions.

Work to develop the SMOD scheme is still ongoing and will include a total non-adiabatic cooling tendency that will account for additional non-adiabatic processes such as turbulent or subgrid mixing. Completing this work could make it easier to incorporate the SMOD scheme into a model such as an NWP model. This is because the non-adiabatic process would be a change in temperature within the grid box rather than requiring an explicit additional term. It was shown that SMOD is sensitive to SOCRATES with regards to the fixed effective radius, especially when considering the decrease in FDNC. Therefore, future work should run the new scheme with the interactive coupling of $r_{\mathrm{e}}$ to CASIM, should the option be available.

As noted in Sect. 5.2, SMOD was unable to capture the fog's spatial variability during initial formation. Poku et al. (2019) discussed how using a more realistic activation scheme such as SMOD would be a suitable solution, as the FDNC would be able to capture the fog's transitional period. However, although our work has shown that
SMOD may be a better option than Shipway, our simulations were not able to simulate the initial fog formation variability and remain stable throughout the night. This feature may have been due to our study using a bulk microphysics scheme, and more specifically a saturation adjustment condensation calculation, which has shown to be problematic in other cloud regimes e.g. deep convective clouds (Lebo et al., 2012) and stratocumulus clouds (Thouron et al., 2012). Previous LES studies of IOP1 (e.g. Boutle et al., 2018) have addressed this limitation by using a prognostic for supersaturation, which in their works led to a reasonable transition when the fog became optically thick. In addition, Schwenkel and Maronga (2020) proposed moving away from bulk microphysics schemes and instead used a Lagrangian cloud model (LCM), which can account for small droplets and swollen aerosols (for context, our results do not capture changes in the drop-size distribution with aerosol activation representation). Therefore, future work should include simulating IOP1 using an LCM, which could be capable of improving the capturing of features of a thin fog.

Since the motivation for our study was to develop and test a suitable scheme that could be used in NWPs to account for aerosol impacts in fog, an LCM mechanism may be unsuitable in an NWP due to additional computational expense. Furthermore, using a prognostic for supersaturation is unsuitable due to the time step for changes in supersaturation being too small for most NWPs (Morrison and Gettelman, 2008). Miltenberger et al. (2018) showed that by including in-cloud aerosol removal the source of aerosol began depleting through nucleation, resulting in a more-open-cell cloud structure and changes in the cloud dynamics. As this study was done using a bulk microphysics scheme, this may be a suitable option when testing the SMOD scheme. To date, there are no studies that have investigated the use of a nucleation scavenging parameterisation in fog in the context of bulk microphysical parameterisations, therefore suggesting a future piece of work within the subject of aerosol-fog interactions. For this work, there was a lack of simultaneous measurements of observed aerosol and cloud droplets. Given the $w_{\text {min }}$ 's sensitivity to aerosol concentration, having these measurements in future studies will both help constrain the model and highlight any further discrepancies in aerosol activation representation in fog. Finally, our study has focused on the first $10 \mathrm{~h}$ of IOP1 and hence has not accounted for the fog evolution during daytime. Given the impact additional processes such as aerosol-radiation interactions and an interactive surface scheme will have on fog dissipation, it is critical to ensure schemes such as SOCRATES and CASIM are coupled for this future work.

As a wider implication, aerosol-cloud interactions are a big source of uncertainty when modelling atmospheric processes, both within forecasting (NWP) and climate (GCM) models, and the choice of aerosol activation can influence how big this uncertainty is. Typically, the resolution of NWP and GCM model simulations is very coarse compared to 
LES, meaning that any present updraught velocities are usually subgrid and hence cannot be resolved. To represent aerosol activation on a subgrid level, the vertical velocity is either in the form a characteristic vertical velocity (e.g. Ghan et al., 1997) or a probability density function (PDF) based on the vertical velocity (e.g. West et al., 2014). More recently, Malavelle et al. (2014), for example, discussed methods to account for subgrid velocities used in aerosol activation in convection-permitting models. These methods utilise a $w_{\min }$; however, this should be lowered systematically for future work regarding aerosol activation in fog. Although gaining measurements of vertical velocity PDFs could be difficult in fog, the results presented in this paper could provide a useful framework to estimate what the variation in vertical velocities in fog could be, therefore providing a good estimation of the types of distributions that best match these velocities. Finally, to have a full cooling term applied in an NWP model, it is important to know how these vertical velocities correlate with the changes in non-adiabatic cooling.

This paper has shown the need to differentiate between optically thin fog $\left(w_{\min } \approx 0 \mathrm{~m} \mathrm{~s}^{-1}\right)$ and optically thick fog, where subgrid vertical velocities can be important. The method being presented in this work is computationally efficient and provided an additional level of flexibility to consider different cooling sources in cases where updraughts are not the dominant cooling source. Given this flexibility, this will allow the SMOD scheme to undergo further testing in both high-resolution and NWP models. Whilst this has been tested in only the Shipway and SMOD activation schemes, the framework for a change in supersaturation is generic enough for it to be applied to other activation schemes too. 


\section{Appendix A: Mathematical formulation for the change in supersaturation}

Pruppacher and Klett (2010) defined supersaturation in terms of the water vapour mixing ratio, $q_{\mathrm{v}}$, as

$q_{\mathrm{v}}=(1+s)\left(\frac{\epsilon e_{\mathrm{s}}}{p}\right)$,

where $p$ is the pressure of dry air; $s$ is the environment's supersaturation; $e_{\mathrm{s}}$ is the saturation vapour pressure; and $\epsilon=$ $\frac{R_{\mathrm{a}}}{R_{\mathrm{v}}}=0.622$, which is the ratio of the gas constant of dry air to water vapour. Differentiating Eq. (A1) with respect to time and rearranging for the change in supersaturation gives

$\frac{\mathrm{d} s}{\mathrm{~d} t}=\left(\frac{p}{\epsilon e_{\mathrm{S}}}\right) \frac{\mathrm{d} q_{\mathrm{v}}}{\mathrm{d} t}-(1+s)\left[\frac{1}{e_{\mathrm{S}}} \frac{\mathrm{d} e_{\mathrm{S}}}{\mathrm{d} t}-\frac{1}{p} \frac{\mathrm{d} p}{\mathrm{~d} t}\right]$.

The Clausius-Clapeyron equation is defined as

$\frac{\mathrm{d} e_{\mathrm{s}}}{\mathrm{d} T}=\frac{L e_{\mathrm{s}}}{R_{\mathrm{V}} T^{2}}$,

with $L$ being defined as specific latent heat. Applying the chain rule gives

$$
\begin{aligned}
\frac{\mathrm{d} e_{\mathrm{s}}}{\mathrm{d} t} & =\left.\frac{L e_{\mathrm{s}}}{R_{\mathrm{v}} T^{2}} \frac{\mathrm{d} T}{\mathrm{~d} t}\right|_{\mathrm{tot}} \\
& =\frac{L e_{\mathrm{s}}}{R_{\mathrm{v}} T^{2}}\left[\left.\frac{\mathrm{d} T}{\mathrm{~d} t}\right|_{\mathrm{ad}}+\left.\frac{\mathrm{d} T}{\mathrm{~d} t}\right|_{\text {non_ad }}+\left.\frac{\mathrm{d} T}{\mathrm{~d} t}\right|_{\text {lat }}\right] .
\end{aligned}
$$

$\left.\frac{\mathrm{d} T}{\mathrm{~d} t} t\right|_{\mathrm{ad}}$ is the change in temperature due to dry adiabatic processes, such that

$\left.\frac{\mathrm{d} T}{\mathrm{~d} t}\right|_{\mathrm{ad}} \equiv-\Gamma \frac{\mathrm{d} z}{\mathrm{~d} t}=-\Gamma w$,

where $\Gamma=\frac{g}{c_{p}}$, which is the dry adiabatic lapse rate, with $c_{p}$ being the specific heat capacity, and $w$ is the updraught velocity. $\left.\frac{\mathrm{d} T}{\mathrm{~d} t}\right|_{\text {non_ad }}$ is the change in temperature due to nonadiabatic processes (e.g. radiative cooling, turbulent mixing), which excludes latent heat release, and $\left.\frac{\mathrm{d} T}{\mathrm{~d} t}\right|_{\text {lat }}$ is the change in temperature due to latent heat release, i.e. condensation/evaporation. For adiabatic expansion (lifting), there are corresponding pressure and temperature changes (which satisfy the first law of thermodynamics). However, for isobaric non-adiabatic heating processes, there is no change in $p$, but there is a change in $T$ that modifies Eq. (A4). Therefore, for the change in $p$, by

1. assuming hydrostatic equilibrium, where $\frac{\mathrm{d} p}{\mathrm{~d} z}=-\rho g$, and

2. using the equation for the ideal gas law, where $p=$ $\rho R_{\mathrm{a}} T$,

$$
\begin{aligned}
\frac{\mathrm{d} p}{\mathrm{~d} t} & =\frac{\mathrm{d} p}{\mathrm{~d} z} \frac{\mathrm{d} z}{\mathrm{~d} t} \\
& =-\frac{p g}{R_{\mathrm{a}} T} w .
\end{aligned}
$$

The change in temperature due to latent heat release is proportional to the change in vapour mixing ratio, such that

$\left.\frac{\mathrm{d} T}{\mathrm{~d} t}\right|_{\text {lat }}=-\left.\frac{L}{c_{p}} \frac{\mathrm{d} q_{\mathrm{v}}}{\mathrm{d} t}\right|_{\text {cond }}=\frac{L}{c_{p}} \frac{\mathrm{d} q_{1}}{\mathrm{~d} t}$.

Inserting Eqs. (A4), (A6) and (A7) into Eq. (A2) and assuming $1+s \approx 1$ gives

$$
\begin{aligned}
\frac{\mathrm{d} s}{\mathrm{~d} t} & =\left(\frac{L g}{R_{\mathrm{v}} T^{2} c_{p}}-\frac{g}{R_{\mathrm{a}} T}\right) w-\left.\frac{L}{R_{\mathrm{v}} T^{2}} \frac{\mathrm{d} T}{\mathrm{~d} t}\right|_{\text {non_ad }} \\
& -\left(\frac{p}{\epsilon e_{\mathrm{S}}}+\frac{L^{2}}{R_{\mathrm{v}} c_{p} T^{2}}\right) \frac{\mathrm{d} q_{1}}{\mathrm{~d} t} .
\end{aligned}
$$

Equation (A8) can be used to simulate aerosol activation in both fog and convective cloud regimes, highlighting the flexibility of the SMOD scheme. As an objective for this work is to understand how using an adiabatic framework to represent aerosol activation in an non-adiabatic environment (e.g. fog) may impact $N_{\text {act }}, w$ in Eq. (A8) will be rewritten as $\left.\frac{\mathrm{d} T}{\mathrm{~d} t}\right|_{\text {ad }}$, such that

$\frac{\mathrm{d} s}{\mathrm{~d} t}=\left.\psi_{1} \frac{\mathrm{d} T}{\mathrm{~d} t}\right|_{\mathrm{ad}}+\left.\psi_{2} \frac{\mathrm{d} T}{\mathrm{~d} t}\right|_{\text {non_ad }}-\gamma \frac{\mathrm{d} q_{1}}{\mathrm{~d} t}$,

where

$$
\begin{aligned}
& \psi_{1}=\frac{c_{p}}{R_{\mathrm{a}} T}-\frac{L}{R_{\mathrm{v}} T^{2}}, \\
& \psi_{2}=-\frac{L}{R_{\mathrm{v}} T^{2}}, \\
& \gamma=\frac{L^{2}}{\epsilon e_{\mathrm{s}}}+\frac{L_{\mathrm{v}} c_{p} T^{2}}{R^{2}} .
\end{aligned}
$$


Appendix B: Fitting modelled LWP and cloud drop-size distribution to observations - shape parameter

All tests in this paper assume a fixed $r_{\mathrm{e}}$, implying that the change in liquid water is controlled by the sedimentation rate, as discussed in Poku et al. (2019). The sedimentation rate is controlled by the cloud drop-size distribution (see Eq. 11), with its skewness being determined by the shape parameter, $\mu_{\mathrm{d}}$. Mazoyer et al. (2017) adapted the default shape parameter to best fit the modelled cloud drop-size distribution to observations. For this work, a similar approach would have ideally been chosen to find a suitable $\mu_{\mathrm{d}}$ to capture the changes in liquid water. However, the instrumentation only began to record spectra during IOP1 $4 \mathrm{~h}$ into the observed fog case, and by this time, the layer had already begun to grow in optical thickness. To account for this limitation, the LWP was used to decide on a suitable choice of $\mu_{\mathrm{d}}$. These simulations were then compared to the available IOP1 cloud spectra data to validate and hence choose a $\mu_{\mathrm{d}}$ going forward. For this fitting, $\mu_{\mathrm{d}}$ ranged from 0 to 3 , with these tests denoted as T_mu_0, T_mu_1, T_mu_2 and T_mu_3 respectively. Although simulations were conducted to increase the shape parameter up to a value of $\mu_{\mathrm{d}}=7$ (similar to Mazoyer et al., 2017), the LWP for tests where $\mu_{\mathrm{d}}>4$ were higher than the observed mean LWP, and hence these results will not be shown.

Both the surface deposition rate and LWP increase with $\mu_{\mathrm{d}}$ (Fig. B1a-b), with this increase being more in line with observations. T_mu_2 and T_mu_3 both show improved LWP when compared to observations, especially before 22:00 UTC. As there are potentially multiple options in choosing $\mu_{\mathrm{d}}$, the modelled cloud drop-size distribution was compared to observations, as shown in Fig. B2. Before 22:00 UTC, all shape parameter tests began with an abundance of small droplets, signalling the formation of fog, with the density of small droplets being greatest in T_mu_0 (not shown). During fog evolution, all tests begin moving right in terms of skewness with the exception for T_mu_0 (due to T_mu_0 being logarithmic). For the tests where $\mu_{\mathrm{d}}>0$, increasing the shape parameter results in the peak of the distribution decreasing and moving to the right, for all tested time frames. For example, increasing the shape parameter to $\mu_{\mathrm{d}}=3$ results in a peak droplet diameter of $11 \mu \mathrm{m}$. These results suggest a limitation in the default choice in $\mu_{\mathrm{d}}=0$ and hence the assumption of a logarithmic distribution for fog development during IOP1. By increasing the shape parameter during the fog evolution, fewer large droplets will sediment out of the fog layer, therefore explaining the presence of bigger droplets still within the system in these tests (for example, tests T_mu_1-3).

At 22:00 UTC, the observed cloud droplet spectrum mostly follows a logarithmic distribution; however, later in the night, it evolves more into a bimodal distribution (as seen in Price, 2011). For example, at 00:00 UTC the peaks occur at 8 and $22 \mu \mathrm{m}$. Of the shape parameter tests, the observa-

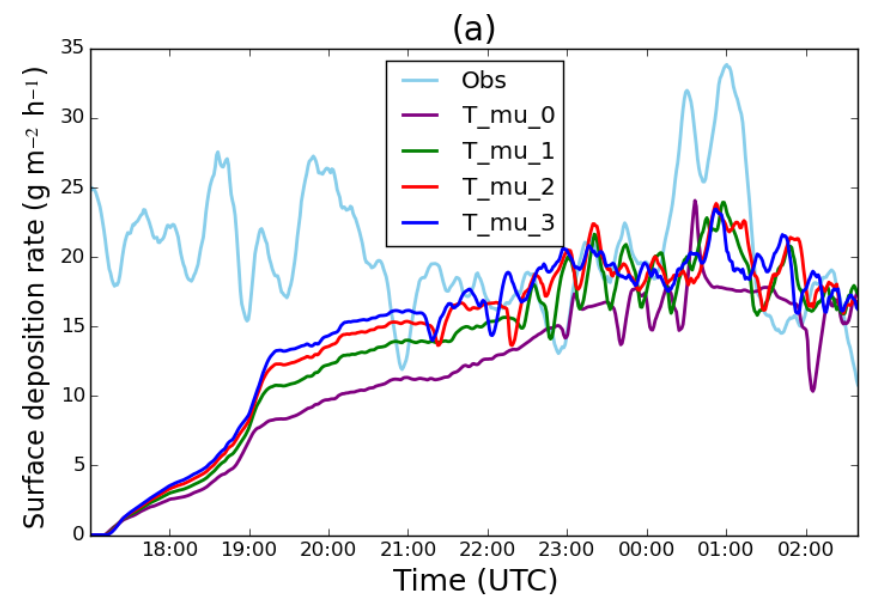

(b)

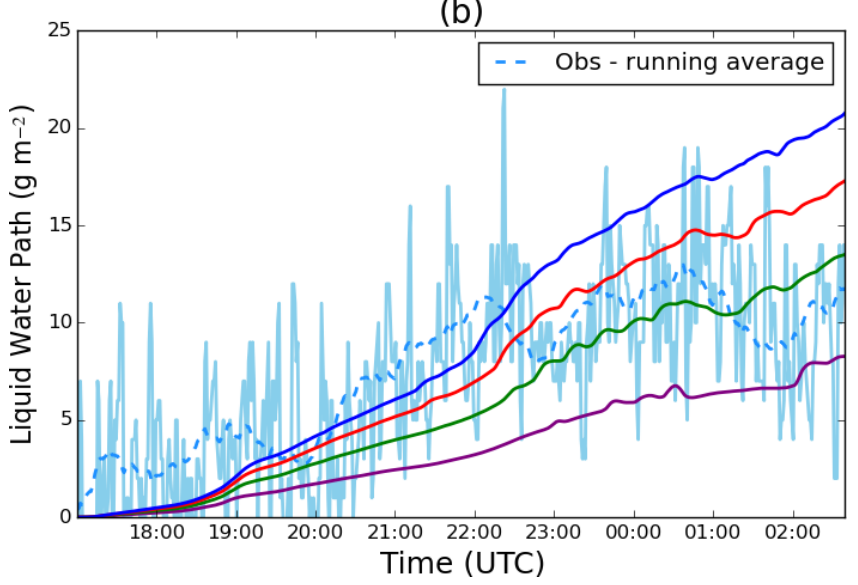

Figure B1. (a) Time series of the surface deposition rate $\left(\mathrm{g} \mathrm{m}^{-2} \mathrm{~h}^{-1}\right)$. Purple - T_mu_0; green - T_mu_0; red - T_mu_1; dark blue - T_mu_3; light blue - observations. (b) Time series of the liquid water path $\left(\mathrm{g} \mathrm{m}^{-2}\right)$. Purple $-\mathrm{T} \_$control; green $-\mathrm{T} \_m u \_1$; red - T_mu_2; dark blue - T_mu_3; light blue - observations; blue dashed line - running average over observations (40 points).

tions are in best agreement with T_mu_3 for droplet size diameters between 22 and $27 \mu \mathrm{m}$ at 00:00 UTC; however, this fit does not take into account the peak shown within the smaller droplets. In an ideal situation, a modelled cloud dropsize distribution would take into account the bimodal nature shown within the distribution. In reality, it is likely that these smaller droplets have not activated but instead are a source of hydrated aerosol which can contribute up to $68 \%$ of the total light scattered, and hence result in the reduction in visibility within the fog (Hammer et al., 2014). However, although these smaller droplets may potentially change the microphysical structure of the fog, the introduction of a bimodal distribution (or a varying shape parameter) within CASIM may increase model computational expense, with no appreciable changes in the fog evolution. Given these results, a shape parameter of $\mu_{\mathrm{d}}=3$ will be used in this paper. 


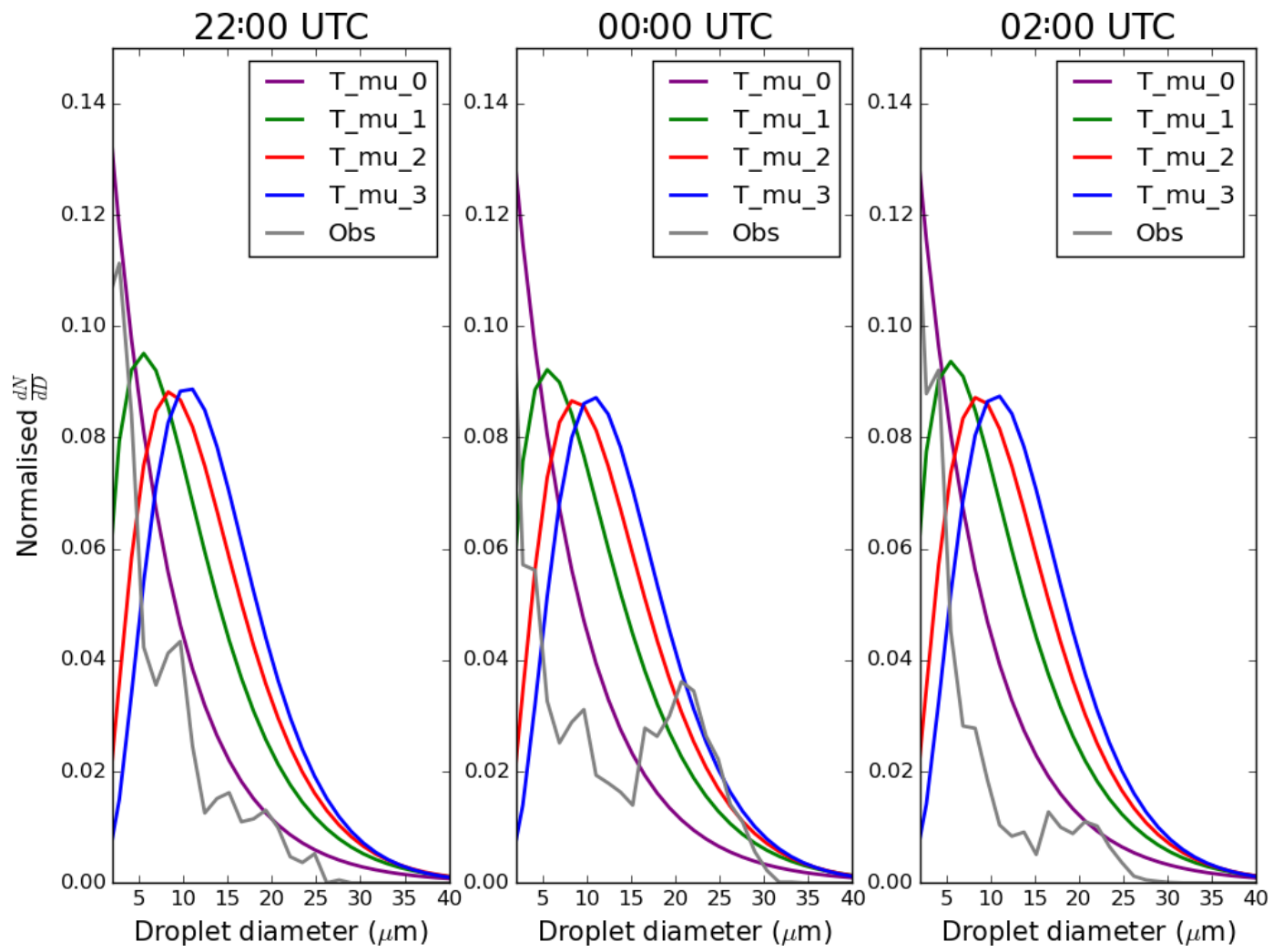

Figure B2. Cloud drop-size distributions for shape parameter simulations at 17:10, 18:00 and 22:00 UTC at $2 \mathrm{~m}$. Green - T_mu_0; red T_mu_1; dark blue -T_mu_3; grey - observations. 
Code availability. The MONC (Brown 2015, 2018), CASIM (Grosvenor et al., 2017; Miltenberger et al., 2018) and SOCRATES (Edward and Slingo, 1996) codes are maintained by the Met Office and are accessible via the Met Office Science Repository Service (https://code.metoffice.gov.uk/) (last access: 8 April 2021). For our work, the MONC branch is available at https://code.metoffice.gov.uk/svn/monc/main/branches/ dev/craigpoku/r6496_MONC_poku_activation (last access: 8 April 2021). For our work, the CASIM branch is available at https://code.metoffice.gov.uk/svn/monc/casim/branches/ dev/craigpoku/vn0.3.2_poku_scheme_debugged (last access: 8 April 2021). For our work, the offline box model branch is available at https://code.metoffice.gov.uk/svn/monc/casim/ branches/dev/craigpoku/r287_Offline_Activation (last access: 8 April 2021). For further details regarding gaining access to the code repositories discussed in this work, please contact Adrian Hill (adrian.hill@metoffice.gov.uk).

Data availability. To obtain access to the observational dataset used in this study, please contact Jeremy Price, who is based at the Met Office Research Unit in Cardington (UK) at jeremy.price@metoffice.gov.uk.

Author contributions. CP undertook the research, carried out the simulations and analysis, and led the writing of the paper. ANR, $\mathrm{AMB}$ and $\mathrm{AAH}$ contributed to the research design, interpretation of the results and the writing of the final paper. AAH provided technical support with MONC. BS provided the box model and supported its use.

Competing interests. The authors declare that they have no conflict of interest.

Acknowledgements. The authors would like to thank the Met Office Research Unit in Cardington (UK) for providing and processing the observational dataset used throughout this study. This work used Monsoon2, a collaborative high-performance computing facility funded by the Met Office and the Natural Environment Research Council. The authors would like to thank the anonymous reviewers for comments that helped improve the quality of this paper.

Financial support. This research has been supported by the Natural Environment Research Council (NERC) Industrial CASE award with the Met Office (grant no. NE/M009955/1).

Review statement. This paper was edited by Johannes Quaas and reviewed by two anonymous referees.

\section{References}

Abdul-Razzak, H. and Ghan, S. J.: A parameterization of aerosol activation: 2. Multiple aerosol types, J. Geophys. Res.-Atmos., 105, 6837-6844, https://doi.org/10.1029/1999JD901161, 2000.

Abdul-Razzak, H., Ghan, S. J., and Rivera-Carpio, C.: A parameterization of aerosol activation: 1. Single aerosol type, J. Geophys. Res.-Atmos., 103, 6123-6131, https://doi.org/10.1029/97JD03735, 1998.

Abramowitz, M. and Stegun, I. A.:Handbook of mathematical functions with formulas, graphs, and mathematical tables, US Government printing office, 55, 1964.

Albrecht, B. A.: Aerosols, cloud microphysics, and fractional cloudiness, Science, 245, 1227-1230, https://doi.org/10.1126/science.245.4923.1227, 1989.

BBC: Sheppey crossing crash: Dozens hurt as 130 vehicles crash, BBC News, available at: https://www.bbc.co.uk/news/ uk-england-kent-23970047 (last access: 5 May 2021), 2013.

Bergot, T., Escobar, J., and Masson, V.: Effect of small-scale surface heterogeneities and buildings on radiation fog: Large-eddy simulation study at Paris-Charles de Gaulle airport, Q. J. Roy. Meteor. Soc., 141, 285-298, https://doi.org/10.1002/qj.2358, 2015.

Bierwirth, E., Ehrlich, A., Wendisch, M., Gayet, J.-F., Gourbeyre, C., Dupuy, R., Herber, A., Neuber, R., and Lampert, A.: Optical thickness and effective radius of Arctic boundary-layer clouds retrieved from airborne nadir and imaging spectrometry, Atmos. Meas. Tech., 6, 1189-1200, https://doi.org/10.5194/amt-6-11892013, 2013.

Böing, S. J., Dritschel, D. G., Parker, D. J., and Blyth, A. M.: Comparison of the Moist Parcel-in-Cell (MPIC) model with largeeddy simulation for an idealized cloud, Q. J. Roy. Meteor. Soc., 145, 1868-1881, https://doi.org/10.1002/qj.3532, 2019.

Bott, A.: On the influence of the physico-chemical properties of aerosols on the life cycle of radiation fogs, Bound.-Lay. Meteorol., 56, 1-31, https://doi.org/10.1007/BF00119960, 1991.

Boutle, I., Price, J., Kudzotsa, I., Kokkola, H., and Romakkaniemi, S.: Aerosol-fog interaction and the transition to well-mixed radiation fog, Atmos. Chem. Phys., 18, 7827-7840, https://doi.org/10.5194/acp-18-7827-2018, 2018.

Brown, N., Weiland, M., Hill, A., Shipway, B., Maynard, C., Allen, T., and Rezny, M.: A Highly Scalable Met Office NERC Cloud Model, in: Proceedings of the 3rd International Conference on Exascale Applications and Software, University of Edinburgh, Edinburgh, UK, 21-23 April 2015, 132-137, available at: https://dl.acm.org/citation.cfm?id=2820083.2820108 (last access: 5 May 2021), 2015.

Brown, N., Weiland, M., Hill, A., and Shipway, B.: In situ data analytics for highly scalable cloud modelling on Cray machines, Concurr. Comp.-Pract. E., 30, e4331, https://doi.org/10.1002/cpe.4331, 2018.

Cohard, J.-M., Pinty, J.-P., and Bedos, C.: Extending Twomey's Analytical Estimate of Nucleated Cloud Droplet Concentrations from CCN Spectra, J. Atmos. Sci., 55, 3348-3357, https://doi.org/10.1175/15200469(1998)055<3348:ETSAEO>2.0.CO;2, 1998.

Dearden, C., Hill, A., Coe, H., and Choularton, T.: The role of droplet sedimentation in the evolution of low-level clouds over southern West Africa, Atmos. Chem. Phys., 18, 14253-14269, https://doi.org/10.5194/acp-18-14253-2018, 2018. 
Ducongé, L., Lac, C., Vié, B., Bergot, T., and Price, J. D.: Fog in heterogeneous environments: the relative importance of local and non-local processes on radiative-advective fog formation, Q. J. Roy. Meteor. Soc., 146, 2522-2546, https://doi.org/10.1002/qj.3783, 2020.

Edwards, J. M. and Slingo, A.: Studies with a flexible new radiation code, I: Choosing a configuration for a largescale model, Q. J. Roy. Meteor. Soc., 122, 689-719, https://doi.org/10.1002/qj.49712253107, 1996.

Gerber, H.: Supersaturation and Droplet Spectral Evolution in Fog, J. Atmos. Sci., 48, 2569-2588, https://doi.org/10.1175/15200469(1991)048<2569:SADSEI>2.0.CO;2, 1991.

Ghan, S. J., Chung, C. C., and Penner, J. E.: A parameterization of cloud droplet nucleation, part I: single aerosol type, Atmos. Res., 30, 198-221, https://doi.org/10.1016/01698095(93)90024-I, 1993.

Ghan, S. J., Leung, L. R., Easter, R. C., and Abdul-Razzak, H.: Prediction of cloud droplet number in a general circulation model, J. Geophys. Res.-Atmos., 102, 21777-21794, https://doi.org/10.1029/97JD01810, 1997.

Gray, M. E. B., Petch, J., Derbyshire, S. H., Brown, A. R., Lock, A. P., Swann, H. A., and Brown, P. R. A.: Version 2.3 of the Met. Office large eddy model, Met Office (APR) Turbulence and Diffusion Rep., 276, 2001.

Grosvenor, D. P., Field, P. R., Hill, A. A., and Shipway, B. J.: The relative importance of macrophysical and cloud albedo changes for aerosol-induced radiative effects in closed-cell stratocumulus: insight from the modelling of a case study, Atmos. Chem. Phys., 17, 5155-5183, https://doi.org/10.5194/acp17-5155-2017, 2017.

Gultepe, I., Boybeyi, Z., and Gultepe, I.: A New Visibility Parameterization for Warm-Fog Applications in Numerical Weather Prediction Models, J. Appl. Meteorol. Clim., 45, 1469-1480, https://doi.org/10.1175/JAM2423.1, 2006.

Gultepe, I., Tardif, R., Michaelides, S. C., Cermak, J., Bott, A., Bendix, J., Müller, M. D., Pagowski, M., Hansen, B., Ellrod, G., Jacobs, W., Toth, G., and Cober, S. G.: Fog research: A review of past achievements and future perspectives, Pure Appl. Geophys., 164, 1121-1159, 2007.

Haeffelin, M., Dupont, J. C., Boyouk, N., Baumgardner, D., Gomes, L., Roberts, G., and Elias, T.: A Comparative Study of Radiation Fog and Quasi-Fog Formation Processes During the ParisFog Field Experiment 2007, Pure Appl. Geophys., 170, 2283-2303, https://doi.org/10.1007/s00024-013-0672-z, 2013.

Hammer, E., Gysel, M., Roberts, G. C., Elias, T., Hofer, J., Hoyle, C. R., Bukowiecki, N., Dupont, J.-C., Burnet, F., Baltensperger, U., and Weingartner, E.: Size-dependent particle activation properties in fog during the ParisFog 2012/13 field campaign, Atmos. Chem. Phys., 14, 10517-10533, https://doi.org/10.5194/acp-1410517-2014, 2014

Hill, A. A., Dobbie, S., and Yin, Y.: The impact of aerosols on nonprecipitating marine stratocumulus, I: Model description and prediction of the indirect effect, Q. J. Roy. Meteor. Soc., 134, 11431154, https://doi.org/10.1002/qj.278, 2008.

IPCC: Climate Change 2001: The Scientific Basis, Cambridge University Press, Cambridge, UK, 2001.

Kiehl, J. T. and Trenberth, K. E.: Earth's Annual Global Mean Energy Budget, B. Am. Meteorol.
Soc., 78, 197-208, https://doi.org/10.1175/1520 0477(1997)078<0197:EAGMEB>2.0.CO;2, 1997.

Lebo, Z. J., Morrison, H., and Seinfeld, J. H.: Are simulated aerosolinduced effects on deep convective clouds strongly dependent on saturation adjustment?, Atmos. Chem. Phys., 12, 9941-9964, https://doi.org/10.5194/acp-12-9941-2012, 2012.

Maalick, Z., Kühn, T., Korhonen, H., Kokkola, H., Laaksonen, A., and Romakkaniemi, S.: Effect of aerosol concentration and absorbing aerosol on the radiation fog life cycle, Atmos. Environ., 133, 26-33, 2016.

Malavelle, F. F., Haywood, J. M., Field, P. R., Hill, A. A., Abel, S. J., Lock, A. P., Shipway, B. J., and McBeath, K.: A method to represent subgrid-scale updraft velocity in kilometer-scale models: Implication for aerosol activation, J. Geophys. Res.-Atmos., 119, 4149-4173, https://doi.org/10.1002/2013JD021218, 2014.

Maronga, B. and Bosveld, F. C.: Key parameters for the life cycle of nocturnal radiation fog: a comprehensive large-eddy simulation study, Q. J. Roy. Meteor. Soc., 143, 2463-2480, https://doi.org/10.1002/qj.3100, 2017.

Mazoyer, M., Lac, C., Thouron, O., Bergot, T., Masson, V., and Musson-Genon, L.: Large eddy simulation of radiation fog: impact of dynamics on the fog life cycle, Atmos. Chem. Phys., 17, 13017-13035, https://doi.org/10.5194/acp-17-13017-2017, 2017.

Meskhidze, N., Nenes, A., Conant, W. C., and Seinfeld, J. H.: Evaluation of a new cloud droplet activation parameterization with in situ data from CRYSTAL-FACE and CSTRIPE, J. Geophys. Res.-Atmos., 110, D16, https://doi.org/10.1029/2004JD005703, 2005.

Miltenberger, A. K., Field, P. R., Hill, A. A., Rosenberg, P., Shipway, B. J., Wilkinson, J. M., Scovell, R., and Blyth, A. M.: Aerosol-cloud interactions in mixed-phase convective clouds Part 1: Aerosol perturbations, Atmos. Chem. Phys., 18, 31193145, https://doi.org/10.5194/acp-18-3119-2018, 2018.

Morrison, H. and Gettelman, A.: A New Two-Moment Bulk Stratiform Cloud Microphysics Scheme in the Community Atmosphere Model, Version 3 (CAM3), Part I: Description and Numerical Tests, J. Climate, 21, 3642-3659, https://doi.org/10.1175/2008JCLI2105.1, 2008.

Nenes, A. and Seinfeld, J. H.: Parameterization of cloud droplet formation in global climate models, J. Geophys. Res.-Atmos., 108, 4415, https://doi.org/10.1029/2002JD002911, 2003.

Poku, C., Ross, A. N., Blyth, A. M., Hill, A. A., and Price, J. D.: How important are aerosol-fog interactions for the successful modelling of nocturnal radiation fog?, Weather, 74, 237-243, https://doi.org/10.1002/wea.3503, 2019.

Porson, A., Price, J., Lock, A., and Clark, P.: Radiation Fog, Part II: Large-Eddy Simulations in Very Stable Conditions, Bound.Lay. Meteorol., 139, 193-224, https://doi.org/10.1007/s10546010-9579-8, 2011.

Price, J.: Radiation Fog, Part I: Observations of Stability and Drop Size Distributions, Bound.-Lay. Meteorol., 139, 167-191, https://doi.org/10.1007/s10546-010-9580-2, 2011.

Price, J. D., Lane, S., Boutle, I. A., Smith, D. K. E., Bergot, T., Lac, C., Duconge, L., McGregor, J., Kerr-Munslow, A., Pickering, M., and Clark, R.: LANFEX: a field and modeling study to improve our understanding and forecasting of radiation fog, B. Am. Meteorol. Soc., 99, 2061-2077, https://doi.org/10.1175/BAMS-D-160299.1, 2018. 
Pruppacher, H. R. and Klett, J. D.: Microphysics of Clouds and Precipitation, Atmospheric and Oceanographic Sciences Library, Springer, Dordrecht, The Netherlands, 954 pp., https://doi.org/10.1007/978-0-306-48100-0, 2010.

Roach, W. T., Brown, R., Caughey, S. J., Garland, J. A., and Readings, C. J.: The physics of radiation fog: I - A field study, Q. J. Roy. Meteor. Soc., 102, 313-333, 1976.

Schwenkel, J. and Maronga, B.: Large-eddy simulation of radiation fog with comprehensive two-moment bulk microphysics: impact of different aerosol activation and condensation parameterizations, Atmos. Chem. Phys., 19, 7165-7181, https://doi.org/10.5194/acp-19-7165-2019, 2019.

Schwenkel, J. and Maronga, B.: Towards a Better Representation of Fog Microphysics in Large-Eddy Simulations Based on an Embedded Lagrangian Cloud Model, Atmosphere, 11, 466, https://doi.org/10.3390/atmos11050466, 2020.

Seifert, A. and Heus, T.: Large-eddy simulation of organized precipitating trade wind cumulus clouds, Atmos. Chem. Phys., 13, 5631-5645, https://doi.org/10.5194/acp-13-5631-2013, 2013.

Shipway, B. J.: Revisiting Twomey's approximation for peak supersaturation, Atmos. Chem. Phys., 15, 3803-3814, https://doi.org/10.5194/acp-15-3803-2015, 2015.

Shipway, B. J. and Abel, S. J.: Analytical estimation of cloud droplet nucleation based on an underlying aerosol population, Atmos. Res., 96, 344-355, https://doi.org/10.1016/J.ATMOSRES.2009.10.005, 2010.

Shipway, B. J. and Hill, A. A.: Diagnosis of systematic differences between multiple parametrizations of warm rain microphysics using a kinematic framework, Q. J. Roy. Meteor. Soc., 138, 2196-2211, https://doi.org/10.1002/qj.1913, 2012.

Squires, P.: The Microstructure and Colloidal Stability of Warm Clouds: Part II - The Causes of the Variations in Microstructure, Tellus, 10, 262-271, https://doi.org/10.3402/tellusa.v10i2.9228, 1958.

Stolaki, S., Haeffelin, M., Lac, C., Dupont, J.-C., Elias, T., and Masson, V.: Influence of aerosols on the life cycle of a radiation fog event - A numerical and observational study, Atmos. Res., 151, 146-161, 2015.
Taylor, G. I.: The formation of fog and mist, Q. J. Roy. Meteor. Soc., 43, 241-268, https://doi.org/10.1002/qj.49704318302, 1917.

Thouron, O., Brenguier, J.-L., and Burnet, F.: Supersaturation calculation in large eddy simulation models for prediction of the droplet number concentration, Geosci. Model Dev., 5, 761-772, https://doi.org/10.5194/gmd-5-761-2012, 2012.

Twomey, S.: The nuclei of natural cloud formation part II: The supersaturation in natural clouds and the variation of cloud droplet concentration, Pure Appl. Geophys., 43, 243-249, 1959.

Twomey, S.: Pollution and the planetary albedo, Atmos. Environ., 8, 1251-1256, 1974.

Twomey, S.: The Influence of Pollution on the Shortwave Albedo of Clouds, J. Atmos. Sci., 34, 1149-1152, 1977.

Vié, B., Pinty, J.-P., Berthet, S., and Leriche, M.: LIMA (v1.0): A quasi two-moment microphysical scheme driven by a multimodal population of cloud condensation and ice freezing nuclei, Geosci. Model Dev., 9, 567-586, https://doi.org/10.5194/gmd-9567-2016, 2016.

West, R. E. L., Stier, P., Jones, A., Johnson, C. E., Mann, G. W., Bellouin, N., Partridge, D. G., and Kipling, Z.: The importance of vertical velocity variability for estimates of the indirect aerosol effects, Atmos. Chem. Phys., 14, 6369-6393, https://doi.org/10.5194/acp-14-6369-2014, 2014.

Whitby, K. T.: The physical characteristics of sulfur aerosols, Atmos. Environ., 12, 135-159, 1978.

WMO: International Meteorological Vocabulary, 1966.

Young, G., Jones, H. M., Choularton, T. W., Crosier, J., Bower, K. N., Gallagher, M. W., Davies, R. S., Renfrew, I. A., Elvidge, A. D., Darbyshire, E., Marenco, F., Brown, P. R. A., Ricketts, H. M. A., Connolly, P. J., Lloyd, G., Williams, P. I., Allan, J. D., Taylor, J. W., Liu, D., and Flynn, M. J.: Observed microphysical changes in Arctic mixed-phase clouds when transitioning from sea ice to open ocean, Atmos. Chem. Phys., 16, 13945-13967, https://doi.org/10.5194/acp-16-13945-2016, 2016.

Zhang, X., Musson-Genon, L., Dupont, E., Milliez, M., and Carissimo, B.: On the influence of a simple microphysics parametrization on radiation fog modelling: A case study during ParisFog, Bound.-Lay. Meteorol., 151, 293-315, 2014. 